\title{
Fatores genéticos associados à fibromialgia: uma revisão narrativa
}

\author{
Genetic factors associated with fibromyalgia: a narrative review \\ Factores genéticos asociados con la fibromialgia: una revisión narrativa
}

Recebido: 01/02/2022 | Revisado: 06/02/2022 | Aceito: 09/02/2022 | Publicado: 14/02/2022

\author{
Amanda Susin Merino \\ ORCID: https://orcid.org/0000-0002-9238-1722 \\ Universidade Luterana do Brasil, Brasil \\ E-mail: amandasmerino@gmail.com \\ Daniel Simon \\ ORCID: https://orcid.org/0000-0003-1122-8468 \\ Universidade Luterana do Brasil, Brasil \\ E-mail: daniel.simon@ulbra.br
}

\begin{abstract}
Resumo
A fibromialgia é uma desordem reumática que tem como principal sintoma a dor crônica generalizada acompanhada de um conjunto de sintomas como distúrbio do sono, depressão e fadiga crônica, entre outros. Sua fisiopatologia é complexa, de origem multifatorial, incluindo a influência de fatores genéticos. Já foi demonstrado que indivíduos com fibromialgia apresentam um padrão de agregação familiar e que a probabilidade de um indivíduo desenvolver essa condição é cerca de 50\% atribuída a fatores genéticos. Neste sentido, o presente artigo tem por objetivo realizar uma revisão narrativa da literatura sobre os aspectos genéticos da fibromialgia em seu desenvolvimento e gravidade dos sintomas. Para tal foram feitas buscas nas bases de dados PubMed e Scopus, com a utilização de descritores específicos: "fibromyalgia" e "polymorphism". Polimorfismos que influenciam na modulação da dor, como os que ocorrem em genes da via monoaminérgica ou do metabolismo das catecolaminas, são encontrados com frequência em estudos de associação com a fibromialgia. Porém, outros genes-alvo têm surgido, relacionados às vias responsáveis pelos mecanismos dos mais diversos sintomas que podem acometer esses pacientes, como neuroplasticidade, neurotransmissão, inflamação, vascularização, estresse oxidativo, ciclo celular, entre outros.
\end{abstract}

Palavras-chave: Fibromialgia; Estudos de associação genética; Predisposição genética para doença; Polimorfismo genético.

\begin{abstract}
Fibromyalgia is a rheumatic disorder whose main symptom is chronic generalized pain accompanied by a set of symptoms such as sleep disturbance, depression, and chronic fatigue, among others. Its pathophysiology is complex, of multifactorial origin, including the influence of genetic factors. It has been shown that individuals with fibromyalgia show a pattern of family aggregation and that the probability of an individual developing this condition is about $50 \%$ attributed to genetic factors. In this sense, the present article aims to carry out a narrative review of the literature on the genetic aspects of fibromyalgia in its development and severity of symptoms. To this end, searches were carried out in PubMed and Scopus databases, using specific descriptors: "fibromyalgia" and "polymorphism". Polymorphisms that influence pain modulation, such as those that occur in genes of the monoaminergic pathway or of catecholamine metabolism, are frequently found in studies of association with fibromyalgia. However, other target genes have emerged, related to the pathways responsible for the mechanisms of the most diverse symptoms that can affect these patients, such as neuroplasticity, neurotransmission, inflammation, vascularization, oxidative stress, cell cycle, among others.
\end{abstract}

Keywords: Fibromyalgia; Genetic association studies; Genetic predisposition to disease; Genetic polymorphism.

\section{Resumen}

La fibromialgia es un trastorno reumático cuyo principal síntoma es el dolor crónico generalizado acompañado de un conjunto de síntomas como alteración del sueño, depresión y fatiga crónica, entre otros. Su fisiopatología es compleja, de origen multifactorial, incluyendo la influencia de factores genéticos. Se ha demostrado que los individuos con fibromialgia muestran un patrón de agregación familiar y que la probabilidad de que un individuo desarrolle esta condición es de alrededor del 50\% atribuida a factores genéticos. En este sentido, el presente artículo tiene como objetivo realizar una revisión narrativa de la literatura sobre los aspectos genéticos de la fibromialgia en su desarrollo y severidad de los síntomas. Para ello, se realizaron búsquedas en las bases de datos PubMed y Scopus, utilizando descriptores específicos: "fibromialgia" y "polimorfismo". Los polimorfismos que influyen en la modulación del dolor, como los que ocurren en los genes de la vía monoaminérgica o del metabolismo de las catecolaminas, se encuentran con frecuencia en los estudios de asociación con la fibromialgia. Sin embargo, han surgido otros genes diana, relacionados con las vías responsables de los mecanismos de los más diversos síntomas que pueden afectar a 
estos pacientes, como la neuroplasticidad, la neurotransmisión, la inflamación, la vascularización, el estrés oxidativo, el ciclo celular, entre otros.

Palabras clave: Fibromialgia; Estudios de asociación genética; Predisposición genética a la enfermedad; Polimorfismo genético.

\section{Introdução}

A fibromialgia (FM) é uma desordem reumática que apresenta como principal característica a dor crônica generalizada (Wolfe et al., 1990). Embora a dor seja sua principal característica, pacientes acometidos por essa condição costumam apresentar sintomas associados como distúrbio do sono, rigidez articular, depressão, fadiga crônica, cefaleia, disfunção cognitiva, hipersensibilidade a estímulos externos, sintomas somáticos, distúrbios psiquiátricos, entre outros (Clauw, 2014; Sarzi-Puttini et al., 2020). Sua fisiopatologia e critérios diagnósticos ainda não são um consenso entre médicos e pesquisadores e estão em constante evolução. Sua etiopatogenia é complexa, de origem multifatorial, com fatores de risco que incluem predisposição familiar, estresse, exposição ambiental, polimorfismos genéticos, entre outros (Sarzi-Puttini et al., 2020).

A prevalência global da FM é de 2,7\%, mas apresentando variação entre diferentes populações (Queiroz, 2013; Marques et al., 2017). Na Espanha, por exemplo, a prevalência média é de 2,4\% (Cabo-Meseguer et al., 2017), no Brasil 2,5\% (Senna et al., 2004), em Hong-Kong 0,8\% (Scudds et al., 2006) e na Turquia 8,8\% (Turhanoglu et al. 2008). Diversos fatores influenciam nessa variação, mas ela depende principalmente dos critérios de inclusão utilizados e da população em estudo (Queiroz, 2013). É mais comum em mulheres que em homens, com uma proporção global de 4:1 (Cabo-Meseguer et al., 2017) e um pico de prevalência entre 50-60 anos de idade (Sarzi-Puttini et al., 2020). Estudos associam essa condição a indivíduos com baixo nível de escolaridade, baixo status socioeconômico e que vivem em áreas rurais (Queiroz, 2013; Walitt et al., 2015). Por comprometer as capacidades física e mental, os custos de saúde para pacientes com FM são substanciais, tendo em vista que esses indivíduos recorrem a serviços médicos com frequência quase duas vezes superior à de indivíduos saudáveis e têm sua capacidade laboral diretamente afetada, levando a altas taxas de invalidez (Wolfe et al, 1995; Berger et al, 2007; Lachaine et al, 2010; Walitt et al., 2015).

\section{Diagnóstico e tratamento}

Diversos estudos vêm sendo conduzidos com o objetivo de determinar os critérios mais adequados para o diagnóstico da FM, apesar disso, devido à falta de biomarcadores específicos, lesões orgânicas aparentes e à subjetividade dos sintomas, seu diagnóstico ainda é feito exclusivamente por meio de avaliação clínica (Queiroz, 2013). Dentre esses estudos, destacam-se os realizados pelo Colégio Americano de Reumatologia (ACR, American College of Rheumatology), que ao longo dos anos passaram por adequações conforme novas informações sobre a FM foram surgindo e na medida em que trabalhos se utilizando desses critérios foram sendo avaliados. O primeiro estudo do ACR sobre este tema, publicado em 1990, teve como objetivo estabelecer os critérios para a classificação da FM, que consistiam na combinação de questionário para investigação da dor generalizada e exame físico dos tender points (18 sítios dolorosos específicos à palpação, aos quais o indivíduo deveria apresentar sensibilidade a 11 ou mais) a ser realizado por profissional qualificado. Porém, a investigação focava apenas em sintomas associados à dor generalizada, o que dificultava a distinção de pacientes com FM de outros com dor crônica generalizada (Wolfe et al., 1990). Em 2010, um conjunto revisado de critérios foi publicado pelo ACR, excluindo a avaliação dos tender points e incluindo a avaliação de sintomas característicos da doença (sintomas cognitivos, distúrbios de sono, fadiga e sintomas somáticos) (Wolfe et al., 2010). A exclusão dos tender points deu-se devido à inespecificidade desse instrumento avaliativo, tendo em vista que indivíduos com FM têm sensibilidade em regiões que se estendem por todo o corpo, não somente nos tender points e às quais qualquer pessoa apresenta sensibilidade, pois são regiões naturalmente mais sensíveis. 
Além disso, a sua utilização levou a um aumento na proporção de mulheres afetadas em relação aos homens, uma vez que elas são 10 vezes mais propensas a terem mais de 11 pontos dolorosos que os homens (Harris \& Clauw, 2006). Uma publicação complementar foi divulgada em 2011 com uma pequena modificação que permitia a utilização dos critérios em estudos epidemiológicos e clínicos sem a exigência de um examinador clínico qualificado (autorrelato) (Wolfe et al., 2011). E em 2016, o ACR revisou os estudos que utilizaram os critérios 2010/2011, concluindo por manter os critérios anteriormente estabelecidos - avaliação dos escores do Índice de Dor Generalizada (WPI, Widespread pain index) e da Escala de Gravidade dos Sintomas (SSS, Symptom severity scale) -, porém dando maior ênfase à presença de dor generalizada, a fim de uma compensação pela exclusão da avaliação física por meio dos tender points, já que esse é o principal sintoma dessa condição. Desse modo, ficaram então definidos quatro critérios para o diagnóstico da FM: 1) Presença de dor generalizada, definida como dor em pelo menos 4 das 5 regiões mapeadas (4 quadrantes: acima e abaixo da cintura, divididas em lado esquerdo e lado direito do corpo, mais a dor esquelética axial); 2) Sintomas presentes em um nível similar há pelo menos 3 meses; 3) WPI $\geq 7$ e SSS $\geq 5$ ou WPI de 4-6 e SSS $\geq 9$ ) O diagnóstico de fibromialgia não exclui a presença de outras doenças clinicamente importantes (Wolfe et al., 2016).

Grande parte dos estudos publicados utiliza como base os critérios de inclusão do ACR (1990 e 2010), mas outros frequentemente encontrados são os critérios do London Fibromyalgia Epidemiology Study Screening Questionnaire (LFESSQ) e do Community Oriented Program for the Control of Rheumatic Diseases (COPCORD), além de diagnósticos clínicos, autorrelatos, entre outros (Queiroz, 2013). Outros instrumentos avaliativos podem ser utilizados a fim de refinar o diagnóstico da FM e obter informações adicionais que auxiliem no direcionamento do tratamento do paciente. Um instrumento comumente utilizado é o Questionário de Impacto da FM (FIQ, Fibromyalgia Impact Questionnaire), que tem como finalidade avaliar o impacto da FM na vida do paciente (Burckhardt et al., 1991; Marques et al., 2006) ou sua versão revisada (FIQR, Revised Fibromyalgia Impact Questionnaire) (Bennett et al., 2009; Paiva et al., 2013).

Indivíduos acometidos por essa condição, apesar de compartilharem da condição de dor crônica, apresentam variabilidade individual quanto ao conjunto sintomatológico (Araya-Quintanilla et al., 2020). Por trata-se de uma condição complexa, cujos mecanismos causadores ainda não são completamente conhecidos e, dada a variabilidade de sintomas entre indivíduos, a abordagem terapêutica deve respeitar a individualidade e complexidade de cada paciente, baseando-se nos sintomas físicos e emocionais, com o objetivo de reduzir as queixas globais e melhora da qualidade de vida (Fitzcharles et al., 2013). Por isso, diversos autores têm sugerido um modelo de tratamento multimodal ou multidisciplinar, que agrega diferentes abordagens terapêuticas (farmacológicas e não farmacológicas) de maneira personalizada (Carville et al., 2008; Yunus, 2015; Macfarlane et al., 2017; Araya-Quintanilla et al., 2020; Sarzi-Puttini et al., 2020)

Quanto aos diversos tipos de tratamento disponíveis, uma abordagem com fortes evidências de eficiência é a prática de exercícios físicos em combinação com o trabalho de conscientização do paciente da importância de sua participação ativa no processo (Macfarlane et al., 2017), pois sabe-se que o papel ativo do paciente com relação aos seus cuidados está diretamente relacionado com uma resposta positiva ao tratamento (Clauw, 2014; Sarzi-Puttini et al., 2020). Terapias psicológicas podem ser indicadas para o tratamento de transtornos de humor, por exemplo, e o tratamento farmacológico, tem indicação para casos de dor grave ou distúrbio do sono (Macfarlane et al., 2017). No que diz respeito ao tratamento de doenças crônicas poligênicas, como a FM, a combinação de várias drogas com diferentes mecanismos de ação muitas vezes se faz necessária (Boomershine \& Crofford, 2009; Clauw, 2014).

Dentre os tratamentos não farmacológicos, destacam-se, além da prática de exercícios físicos e terapias psicológicas, a terapia mental e corporal (termo heterogêneo utilizado para se referir a atividades de terapia do movimento meditativo, como qigong e Tai chi, ambas práticas da arte marcial chinesa), yoga, massagem terapêutica e acupuntura (Chinn et al., 2016; SarziPuttini et al., 2020). Mais recentemente as técnicas neuromodulatórias como, por exemplo, a estimulação transcraniana por 
corrente contínua (tDCS, Transcranial direct current stimulation), têm demonstrado potencial para diminuir a intensidade da dor em condições de dor crônica como a FM, além de se mostrar uma prática segura (Meeker et al., 2020; Lloyd et al., 2020).

\section{Fisiopatologia}

Nos últimos anos, diversos estudos vêm sendo realizados a fim de compreender a fisiopatologia da FM. Alguns desses estudos encontraram correlações com as mais diversas condições, tais como síndromes do sistema nervoso central (SNC), comorbidades, fatores ambientais, psicológicos e genéticos (Clauw, 2014).

Evidências sugerem que o principal sintoma da FM, a dor crônica generalizada, seja resultante de uma alteração na função padrão da dor (nocicepção) causada por modificações neuromorfológicas, denominada dor nociplástica. Nesse caso a dor persiste mesmo após o término do estímulo original ou é desencadeada por estímulo inócuo, sem claras evidências de dano tecidual real ou potencial ao sistema nervoso e seria resultado da interação de diversos mecanismos como, eventos de vida estressantes, predisposição genética, mecanismos centrais e periféricos (Sluka \& Clauw, 2016; Sarzi-Puttini et al., 2020). Nesse contexto, a sensibilização central (SC) surgiu como um importante conceito para explicar a dor crônica na FM e em outras condições de dor crônica. A SC pode ser definida como um processamento anormal dos sinais sensoriais de transmissão e inibição da dor, devido a um estado de hiperexcitação do SNC, no qual a sensação dos sinais normais é amplificada pela redução do limiar da dor, levando à dor crônica. No contexto clínico, a SC explica a dor crônica generalizada como uma sensibilidade excessiva dos pacientes a uma série de estímulos periféricos nocivos (calor e pressão, entre outros) e não nocivos (toque suave, por exemplo), e também a estímulos ambientais, como exposição à luz, ruídos e componentes químicos, entre outros (Yunus, 2015).

Pacientes com FM frequentemente apresentam comorbidades associadas que acabam por influenciar no curso da doença e, por muitas vezes, dificultam seu diagnóstico e tratamento (Bilge et al., 2018). Doenças reumatológicas (artrite reumatoide, lúpus e osteoartrite), doenças neurológicas (esclerose múltipla e doença de Parkinson), doenças internas (gastrointestinais, endócrinas e obesidade), outras síndromes funcionais dolorosas, transtornos mentais e transtornos do sono são categorias de comorbidades que podem estar associadas (Fitzcharles et al., 2018).

A combinação de depressão e dor crônica é frequentemente encontrada nos pacientes com FM. Ambas as condições compartilham as mesmas vias descendentes no SNC e resultam de um desequilíbrio neuroquímico dos neurotransmissores monoaminérgicos: serotonina, norepinefrina e dopamina (Bair et al., 2003). Entre 70 e $90 \%$ dos pacientes relatam distúrbios do sono, que estão associados à fadiga e maior gravidade dos sintomas, além de pior percepção da qualidade do sono (Borchers \& Gershwin, 2015). A associação entre dor e distúrbio do sono em pacientes com FM é bidirecional, ou seja, maior dor implica pior qualidade do sono, e uma noite de sono insuficiente prediz a intensidade da dor no dia seguinte (Affleck et al., 1996). Distúrbios do sono também estão relacionados a sintomas de depressão, ansiedade e a limitações funcionais (Borchers \& Gershwin, 2015). Outros fatores, entre os quais cognitivos, comportamentais e sociais, também contribuem para um prognóstico ruim de estados de dor crônica como a FM (Clauw, 2014). A catastrofização da dor, um fator psicossocial, é uma reação negativa a estímulos dolorosos, caracterizada pelo pensamento de ampliação do desprazer (magnificação), autopercepção do indivíduo como incapaz de controlar os sintomas da dor (desamparo) e uma concentração excessiva nas sensações de dor por pensamentos repetitivos (ruminação) (Sullivan et al., 2006). Indivíduos que catastrofizam a dor tendem a ter mais medo do movimento (cinesiofobia) e de se lesionar, o que leva a um comportamento de desuso, depressão e baixa qualidade de vida, e esse comportamento tende a aumentar a catastrofização levando a um ciclo vicioso (Sullivan et al., 2001; Sullivan et al., 2006). Um fator muito importante para a melhora do prognóstico é a resiliência, que é a capacidade que o indivíduo tem de lidar com a adversidade e o estresse. Essa condição tem a influência de múltiplos fatores, entre os quais epigenéticos, genéticos, neuroquímicos, psicossociais e de desenvolvimento (McAllister et al., 2015). A resiliência está 
diretamente ligada ao enfrentamento de comportamentos negativos, como a catastrofização, em pacientes com dor crônica, como a FM (Karoly \& Ruehlman, 2006).

Tendo em vista a ampla gama de sintomas, fica clara a complexa fisiopatologia da FM e também que é improvável que ela tenha uma etiologia única. Nesse cenário, o fator genético parece ter um importante papel já que se sabe que algumas condições de dor crônica possuem origem multifatorial (Mogil, 2012; Ablin \& Buskila, 2014) e que pacientes com FM, em especial, demonstram um padrão de agregação familiar, indicando que há uma predisposição genética nesses indivíduos (Clauw, 2014; Ablin \& Buskila, 2015). Pacientes com FM têm uma probabilidade maior de possuírem parentes em primeiro grau com FM ou outras condições de dor crônica do que pessoas que não possuem essa condição (Arnold et al., 2004). Estudos de grandes coortes, realizados com gêmeos, sugerem que a probabilidade de um indivíduo desenvolver FM ou outras condições de dor crônica é cerca de 50\% atribuída a fatores genéticos (Reichborn-Kjennerud et al., 2002; Kato et al., 2009; Markkula et al., 2009). Sabe-se também que diversos fatores genéticos são determinantes da maneira pela qual a dor é transmitida e processada pelo sistema nervoso (Ablin \& Buskila, 2014). O presente artigo tem por objetivo realizar uma revisão narrativa da literatura sobre os aspectos genéticos da FM em seu desenvolvimento e gravidade dos sintomas.

\section{Metodologia}

O presente estudo trata-se de uma revisão narrativa da literatura (Pereira, 2012) e para tal foram realizadas buscas nas bases de dados PubMed e Scopus, com a utilização de descritores específicos: "fibromyalgia" e "polymorphism". O processo de pesquisa foi realizado em novembro de 2021. Foram utilizados os seguintes critérios de inclusão: artigos em inglês, com versões completas, sem restrição de período de publicação, sendo que o artigo mais antigo sobre o assunto foi publicado em 1999. A seleção inicial foi feita com base nos títulos e resumos e artigos que analisaram fatores genéticos relacionados à fibromialgia, os quais foram elegíveis para incluir na revisão. Subsequentemente foi realizada uma revisão manual das referências citadas nos artigos originais e artigos de revisão selecionados. Estudos que não apresentavam informações relevantes em relação ao tema e que não obedeciam aos critérios de inclusão foram excluídos.

\section{Resultados e Discussão}

\section{Fatores genéticos}

Diversas pesquisas têm sido realizadas nos últimos anos visando a compreender quais são os genes relacionados com a fisiopatologia da FM, e qual o papel deles nesta condição. Avanços consideráveis já foram feitos na identificação dos principais contribuintes moleculares para o surgimento e manutenção da dor crônica (Zorina-Lichtenwalter et al., 2016). Genes implicados na via monoaminérgica têm sido amplamente investigados, tendo em vista o que já se avançou na compreensão da fisiopatologia da FM, especialmente no que diz respeito ao conceito da SC no processamento e transmissão da dor. Por isso, polimorfismos em genes relacionados a neurotransmissores e outros componentes que participam dessa via, agindo na modulação da dor como serotonina, norepinefrina, dopamina, entre outros, são frequentemente encontrados em estudos de associação genética com a FM (Lee et al., 2012; Ablin \& Buskila, 2014; Zorina-Lichtenwalter et al., 2016). Porém, outros genes-alvo têm surgido, relacionados às vias responsáveis pelos mecanismos dos mais diversos sintomas que podem acometer esses pacientes, como inflamação, vascularização, estresse oxidativo, ciclo celular, entre outros (Karakus et al., 2012; Yigit et al., 2013; Inanir et al., 2015; da Silveira Alves et al., 2020; Estévez-López et al., 2021b).

\section{Via monoaminérgica - Genes serotonérgicos}

A serotonina (5-hidroxitriptamina, 5-HT) é um neurotransmissor chave no SNC, que exerce importante papel na depressão e na modulação da dor, através de sua sinalização que desempenha funções antidepressivas e antinociceptivas (Doan 
et al., 2015). Com base nisso, estudos foram conduzidos a fim de corroborar a hipótese de disfunção no sistema da 5-HT em pacientes com FM. Alguns deles demonstraram evidências de níveis reduzidos de 5-HT no soro e líquido cefalorraquidiano (LCR) de pacientes com FM (Russell et al., 1992a; Russell et al., 1992b; Wolfe et al., 1997). Um dos principais reguladores do sistema serotonérgico é o receptor 5-hidroxitriptamina 2A (5-HT2A), codificado pelo gene HTR2A, que em humanos está localizado no cromossomo 13q14.2 (Tander et al., 2008). Evidências sugerem que este receptor desempenhe um papel na percepção da dor e na etiologia de várias doenças neuropsiquiátricas (Graeff, 1997; Hannon \& Hoyer, 2008; Żmudzka et al., 2018). O polimorfismo silencioso T102C (rs6313) (transição T para $C$ na posição 102) do gene HTR2A não resulta em qualquer alteração na sequência final de aminoácidos da proteína (Tander et al., 2008), mas tem sido reportado por apresentar associação com algumas doenças psiquiátricas, como esquizofrenia e transtorno de humor (Williams et al., 1996; Żmudzka et al., 2018). Em pacientes com FM o genótipo T/T deste polimorfismo foi associado a um agravamento dos sintomas psiquiátricos (depressão, ansiedade, psicose, entre outros) (Gürsoy et al., 2001) e a uma maior sensibilidade à dor (Bondy et al., 1999). A associação entre o alelo $\mathrm{C}$ do polimorfismo HTR2A rs6313 e a suscetibilidade à FM foi reportada em um estudo de metanálise publicada em 2012 (Lee et al., 2012). Na metanálise, foram analisados conjuntamente três estudos que separadamente não apresentaram associação do polimorfismo com a FM (Bondy et al., 1999; Gürsoy et al., 2001; Tander et al., 2008). Da mesma forma, um estudo conduzido em pacientes brasileiros, que não foi incluído na metanálise, também não demonstrou associação entre o polimorfismo e a FM (Matsuda et al., 2010).

Recentemente o alelo G do polimorfismo rs6311 (-1438A/G), outra variante do gene HTR2A, foi associado a um risco aumentado de desenvolvimento da FM em mulheres caucasianas (de Lima et al., 2019). Esse polimorfismo também já foi associado a condições de dor crônica como a artrite reumatoide (Kling et al., 2008) e a vestibulodinia provocada (Heddini et al., 2014). A variante $-1438 \mathrm{~A} / \mathrm{G}$ está localizada em uma região próxima à região promotora do gene HTR2A, enquanto a variante silenciosa T102C encontra-se no éxon 1 do mesmo gene. Ambas estão em desequilíbrio de ligação quase completo uma com a outra (Spurlock et al., 1998). Já foi demonstrado que o alelo A do polimorfismo rs6311 é responsável por um aumento significativo na atividade da região promotora do gene HTR2A em um estudo com linhagens celulares que expressam esse gene (Parsons et al., 2004).

Outro importante regulador do sistema da 5-HT é o transportador 5-hidroxitriptamina (5-HTT), também conhecido como transportador de soluto da família 6, membro 4, o qual é codificado pelo gene SLC6A4 que está localizado no cromossomo 17q11.2 (Ramamoorthy et al., 1993; Gelernter et al., 1995; Shen et al., 2000). O 5-HTT tem papel fundamental na neurotransmissão serotonérgica, sendo responsável pelo transporte de 5-HT dos espaços sinápticos para neurônios présinápticos (Park et al., 2015). O polimorfismo 5-HTTLPR (rs25531), localizado na região promotora do gene SLC6A4, consiste na inserção ou deleção de 44 pb nesta região, dando origem a um alelo curto (S) ou longo (L) (Heils et al., 1996). Este polimorfismo está situado em uma região rica em $\mathrm{CpG}$, composta por unidades de repetição de 20 a 23 pb, sendo os alelos $\mathrm{S}$ e L compostos por 14 e 16 elementos de repetição, respectivamente (Gursoy, 2002). Diferentes eficiências transcricionais são atribuídas a cada variante, estando a variante $\mathrm{L}$ associada a um aumento de três vezes na atividade transcricional da proteína, o que resulta em uma maior atividade de recaptação de 5-HT quando comparada à variante $\mathrm{S}$ (Heils et al., 1996). O alelo L foi relacionado, de forma dose-dependente, à capacidade de resiliência emocional em um grupo de estudantes californianos (Stein et al., 2009). Pacientes alemães com FM apresentaram frequência aumentada do genótipo S/S em comparação ao grupo controle, e exibiram níveis médios mais elevados de depressão e sofrimento psicológico que os pacientes com os demais genótipos (L/L e L/S) (Offenbaecher et al., 1999). Da mesma forma, o polimorfismo SLC6A4 rs25531 foi associado a traços de personalidade relacionados à ansiedade em um grupo de paciente israelenses com FM, nos quais o genótipo S/S foi mais prevalente em comparação ao grupo controle (Cohen et al., 2002). Também já foi demonstrada associação deste polimorfismo a traços de personalidade relacionados à ansiedade (Lesch, 1996) e, em específico, o alelo $\mathrm{S}$ associado a altos níveis de 
ansiedade e medo (Hariri et al., 2002).

Outro componente do sistema da 5-HT é o receptor 5-hidroxitriptamina-3 (5-HT3). Membro da superfamília de receptores ionotrópicos, é codificado pelo gene HTR3 que, em humanos, está localizado no cromossomo 11q23.2 (Maricq et al., 1991; Miyake et al., 1995; Weiss et al., 1995). Receptores do tipo 5-HT3 são canais catiônicos não seletivos, responsáveis pela resposta excitatória rápida à serotonina (Krzywkowski et al., 2008) e, em geral, têm sido associados com a modulação da resposta à dor no SNC (Cortes-Altamirano et al., 2018). Apresentam duas subunidades homólogas (que possuem $41 \%$ de identidade de sequência), os receptores 5-HT3A (codificado pelo gene HTR3A) e 5-HT3B (codificado pelo gene HTR3B) (Davies et al., 1999). No gene HTR3A, o polimorfismo rs1062613 (c.-42C> T) do tipo 5'UTR (região não codificante do RNA mensageiro), foi associado a um aumento da ansiedade e da responsividade da amígdala (aumento da dor) em pacientes com síndrome do intestino irritável (Kilpatrick et al, 2011). Recentemente um estudo, com um pequeno tamanho amostral, demonstrou uma frequência aumentada do genótipo C/C desse polimorfismo em um grupo de pacientes com FM em relação ao grupo controle (Ledermann et al., 2020).

\section{Outros fatores genéticos associados à via monoaminérgica}

A guanosina trifosfato ciclo-hidrolase (GCH1) é uma enzima com função limitadora da taxa de síntese de tetrahidrobiopterina (BH4) que é um cofator essencial para a produção de catecolaminas, serotonina e óxido nítrico (NO). A GCH1 desempenha um papel importante na modulação da dor neuropática e inflamatória periférica através do controle que ela desempenha na produção de BH4. E sabe-se que o excesso de BH4 está intimamente relacionado ao aumento da sensibilidade à dor (Tegeder et al., 2006). Essa enzima é codificada pelo gene GCH1, que em humanos está localizado no cromossomo 14q22.2 (Thöny et al., 1995). O polimorfismo GCH1 rs841 foi associado com uma suscetibilidade à FM em mulheres espanholas (Estévez-López et al., 2018b). Em outro estudo, que comparou haplótipos de polimorfismos do GCH1, o haplótipo CCTA (rs841, rs752688, rs4411417, rs3783641) conferiu a seus portadores (pacientes com FM) uma sensibilidade à dor significativamente menor, porém, ocorreu em menor frequência que o haplótipo CCTT nesse grupo (Kim et al., 2013).

O gene SCN9A (cromossomo 2q24.3) codifica os canais de sódio voltagem dependente, subunidade alfa (SCN9A) que são nociceptores localizados principalmente nos gânglios da raiz dorsal e neurônios dos gânglios simpáticos (Michiels et al., 2005). Polimorfismos nesse gene têm sido associados a alterações na percepção da dor (Estacion et al., 2009; Reimann et al., 2010) e à eritermalgia autossômica dominante (Michiels et al., 2005). O polimorfismo rs6754031 SCN9A foi associado à FM em um estudo com mulheres mexicanas no qual, pacientes com FM portadoras do genótipo GG apresentaram um aumento significativo da severidade da FM (avaliada através do FIQ) em comparação às pacientes portadoras dos demais genótipos (GT e TT) (Vargas-Alarcon et al., 2012). Outro estudo, de associação genômica ampla (GWAS, Genome Wide Association Studies), que avaliou o papel da suscetibilidade genética e a interação gene-atividade física à fadiga em mulheres com FM, apontou associação dos polimorfismos rs4453709, rs4597545 e rs7607967 desse gene com uma influência da prática de exercícios físicos na sensação de fadiga nesse grupo (Estévez-López et al., 2021a)

A proteína translocadora (TSPO) é um biomarcador da ativação glial que atua como um limitante da taxa de síntese de neuroesteróides. Esses, por sua vez, são um componente importante na transmissão sináptica, de modo que alterações nos níveis de neuroesteróides influenciam diretamente o funcionamento de mecanismos serotonérgicos, tendo repercussões nas vias pró e antinociceptivas e também sendo reportados associados a transtornos psiquiátricos, como ansiedade, por exemplo (Costa et al., 2012). Estudos mostram que polimorfismos no gene TSPO (cromossomo 22q13.2) parecem agir nessas vias, contribuindo assim com um quadro clínico mais grave dos pacientes com FM. O polimorfismo TSPO rs6971 (Ala147Thr) foi associado a uma maior intensidade de dor e sintomas mais graves em pacientes com FM (Kosek et al., 2016). Esse polimorfismo também foi associado a uma inibição da dor descendente menos eficiente e a uma redução da dor induzida pela 
expectativa em pacientes com FM (Fanton et al., 2021).

Os canais de potencial receptor transiente (TRP) são responsáveis pela detecção de diversos estímulos nocivos (mecânicos, térmicos e químicos) e alguns desses canais têm como principal função a detecção de calor e são altamente expressos em vias de dor (Levine \& Alessandri-Haber, 2007). O polimorfismo rs395357 do gene TRPV3 (cromossomo 17p13.2) foi associado a uma severidade da fadiga em pacientes com FM e também, haplótipos do gene (rs7216486 e rs395357) foram associados a uma gravidade dos sintomas de FM neste grupo. Enquanto, nesse mesmo estudo, o haplótipo GTA (rs3813768, rs8121, rs1129235) do gene TRPV2 (cromossomo 17p11.2) apresentou um papel protetor contra a FM (Park et al., 2016b). O SNP rs1799971 do gene do receptor opioide $\mu 1$ (OPRM1), localizado no cromossomo 6q25.2 em humanos, teve seu genótipo GG associado à FM em um estudo com mulheres espanholas (Estévez-López et al., 2018b). O receptor opioide $\mu 1$ (OPRM1) é membro da família dos receptores acoplados à proteína $\mathrm{G}$ e é o principal local de ação dos opioides endógenos e exógenos (Bond et al., 1998). Evidências sugerem baixa disponibilidade de OPRM1 em regiões do cérebro envolvidas na modulação da dor em pacientes com FM, em contraponto com os níveis no líquido cefalorraquidiano que são mais elevados nesses indivíduos em comparação a indivíduos saudáveis (Baraniuk et al., 2004; Harris et al., 2007).

Polimorfismos em receptores de dopamina também foram reportados por estarem associados à FM. O polimorfismo rs6280 (Ser9Gly), que ocorre no gene DRD3 (cromossomo 3q13.31) do receptor de dopamina D3(DRD3), foi associado a limiares de dor reduzidos e a uma inibição da dor deficiente em pacientes com FM (Potvin et al., 2009). O gene DRD4 (cromossomo 11p15.5) que codifica o receptor de dopamina D4 (DRD4) possui diversos polimorfismos em sua região VNTR (48 pb no exon III) que afetam o número de repetições de sua terceira alça intracelular (Chang et al., 1996), dentre eles, o polimorfismo de 7 repetições no éxon III que está associado a traços de personalidade, como a busca por novidades (Ebstein et al., 1996), teve sua frequência determinada em um estudo com pacientes com fibromialgia. Nesse estudo, o alelo de 7 repetições foi significativamente menos frequente em pacientes com fibromialgia, que também apresentaram menor desempenho para o traço de personalidade que busca novidades (Buskila et al., 2004). Os polimorfismos associados à via monoaminérgica estão apresentados na Tabela 1. 
Tabela 1. Polimorfismos em genes associados à via monoaminérgica.

\begin{tabular}{|c|c|c|c|}
\hline Localização & $\begin{array}{c}\text { Genótipo/ } \\
\text { Alelo/ } \\
\text { Haplótipo }\end{array}$ & Associação & Referência \\
\hline \multicolumn{4}{|l|}{ HTR2A (13q14.2) } \\
\hline \multirow[t]{3}{*}{ rs6313 (T102C) } & $\mathrm{T} / \mathrm{T}$ & $\begin{array}{l}\text { Agravamento de sintomas psiquiátricos (depressão, } \\
\text { ansiedade, psicose, entre outros) }\end{array}$ & Gürsoy et al., 2001 \\
\hline & $\mathrm{T} / \mathrm{T}$ & Aumento da sensibilidade à dor & Bondy et al., 1999 \\
\hline & Alelo C & Suscetibilidade à FM & Lee et al., 2012 \\
\hline rs6311 (-1438A/G) & Alelo G & $\begin{array}{l}\text { Risco aumentado de desenvolvimento da FM em } \\
\text { mulheres caucasianas }\end{array}$ & de Lima et al., 2019 \\
\hline \multicolumn{4}{|l|}{$S L C 6 A 4(17 q 11.2)$} \\
\hline \multirow[t]{3}{*}{ rs25531 (5-HTTLPR) } & $\mathrm{S} / \mathrm{S}$ & Suscetibilidade à FM. & Offenbaecher et al., 1999 \\
\hline & & $\begin{array}{l}\text { Níveis médios mais elevados de depressão e sofrimento } \\
\text { psicológico }\end{array}$ & \\
\hline & NA & $\begin{array}{l}\text { Aumento de traços de personalidade relacionados à } \\
\text { ansiedade }\end{array}$ & Cohen et al., 2002 \\
\hline \multicolumn{4}{|l|}{ HTR3A (11q23.2) } \\
\hline rs $1062613($ c. $-42 \mathrm{C}>\mathrm{T})$ & $\mathrm{C} / \mathrm{C}$ & Frequência aumentada do genótipo $\mathrm{C} / \mathrm{C}$ & Ledermann et al., 2019 \\
\hline \multicolumn{4}{|l|}{ GCH1 (14q22.2) } \\
\hline rs841 & NA & Suscetibilidade à FM & Estévez-López et al., 2018b \\
\hline $\begin{array}{l}\text { rs841, rs752688, rs4411417 } \\
\text { e rs3783641 }\end{array}$ & Haplótipo CCTA & Redução da sensibilidade à dor (fator de proteção) & Kim et al., 2013 \\
\hline \multicolumn{4}{|l|}{$S C N 9 A(2 \mathrm{q} 24.3)$} \\
\hline \multirow[t]{2}{*}{ rs6754031 } & NA & Associado à FM & Vargas-Alarcon et al., 2012 \\
\hline & $\mathrm{G} / \mathrm{G}$ & Aumento da severidade da FM & Vargas-Alarcon et al., 2012 \\
\hline $\begin{array}{l}\text { rs } 4453709, \text { rs } 4597545 \\
\quad \text { e rs7607967 }\end{array}$ & NA & Fadiga & Estévez-López et al., 2021a \\
\hline \multicolumn{4}{|l|}{$T S P O(22 q 13.2)$} \\
\hline \multirow[t]{4}{*}{ rs6971 (Ala147Thr) } & NA & Maior intensidade da dor & Kosek et al., 2016 \\
\hline & & Agravamento dos sintomas & \\
\hline & NA & Inibição da dor descendente menos eficiente & Fanton et al., 2021 \\
\hline & & Redução da dor induzida pela expectativa & \\
\hline \multicolumn{4}{|l|}{ TRPV3 (17p13.2) } \\
\hline rs 395357 & NA & Severidade da fadiga & Park et al., 2016b \\
\hline rs7216486 e rs395357 & Haplótipos & Agravamento dos sintomas & Park et al., 2016b \\
\hline \multicolumn{4}{|l|}{ TRPV2 (17p11.2) } \\
\hline rs 3813768, rs8121 e rs1129235 & Haplótipo GTA & Fator de proteção & Park et al., 2016b \\
\hline \multicolumn{4}{|l|}{ OPRM1 (6q25.2) } \\
\hline rs1799971 & $\mathrm{G} / \mathrm{G}$ & Associado à FM & Estévez-López et al., 2018b \\
\hline \multicolumn{4}{|l|}{ DRD3 (3q13.31) } \\
\hline \multirow[t]{2}{*}{ rs6280 (Ser9Gly) } & NA & Redução de limiares da dor & Potvin et al., 2009 \\
\hline & & Deficiência na inibição da dor & \\
\hline \multicolumn{4}{|l|}{ DRD4 (11p15.5 ) } \\
\hline VNTR - 7 repetições - exon III & NA & $\begin{array}{l}\text { Menor desempenho do traço de personalidade que busca } \\
\text { novidades }\end{array}$ & Buskila et al., 2004 \\
\hline
\end{tabular}

NA, não se aplica. VNTR, Variable number of tandem repeats. Fonte: Autores.

\section{Catecolaminas}

A enzima catecol-O-metiltransferase (COMT), está envolvida na degradação metabólica de catecolaminas, incluindo os neurotransmissores dopamina, epinefrina, norepinefrina entre outros (Gogos et al., 1998; Chen et al., 2004). Alterações no sistema da norepinefrina podem estar associadas à depressão e afetar uma ampla gama de funções cognitivas e afetivas (Pertovaara, 2006). Além disso, a sinalização disfuncional da dopamina está relacionada não só com a depressão (Moriam \& Sobhani, 2013; Pearson-Fuhrhop et al., 2014), mas também com o aumento da sensibilidade à dor em condições de dor crônica e a sintomas de distúrbio do sono, concentração reduzida, anedonia, entre outros (Doan et al., 2015). Existem também evidências de níveis reduzidos de dopamina no LCR de pacientes com FM (Russell et al., 1992b).

É codificada pelo gene COMT que em humanos está localizado no cromossomo 22q11.21. Diferentes polimorfismos 
de nucleotídeo único (SNPs, Single nucleotide polymorphisms) identificados para esse gene já foram associados à FM: rs4680, rs6269, rs4818 (Gürsoy et al., 2003; Vargas-Alarcón et al., 2007; Martínez-Jauand et al., 2013). O SNP Val158Met (rs4680), que ocorre no códon 158 deste gene, resulta na transição de uma valina (Val) para uma metionina (Met) e está associado a uma diferença na termoestabilidade que leva a uma redução de três a quatro vezes na atividade da enzima COMT (Cohen et al., 2009). Esses alelos são codominantes e podem dar origem a três genótipos possíveis: o genótipo Val/Val que corresponde a uma alta atividade enzimática, o genótipo $\mathrm{Val} / \mathrm{Met}$ que corresponde a uma atividade enzimática intermediária e o genótipo Met/Met que corresponde a uma baixa atividade enzimática (Chen et al., 2004; Tunbridge, 2010). Estudos já demonstraram associação do genótipo Met/Met desse polimorfismo com diversos sintomas que afetam pacientes com FM. O aumento da sensibilidade à dor foi reportado em pacientes com FM portadores desse genótipo em Israel, no Brasil e na Espanha (Cohen et al., 2009; Barbosa et al., 2012; Martínez-Jauand et al., 2013). Esse mesmo genótipo também foi associado a um aumento da sensibilização central em pacientes com FM da Suíça (Desmeules et al., 2014). Alguns estudos associaram o genótipo Met/Met do SNP Val158Met ao agravamento de fatores psicológicos em pacientes com FM, como ansiedade e depressão (Desmeules et al., 2012; Fernández-de-las-Peñas et al., 2012; Martínez-Jauand et al., 2013) e a níveis reduzidos dos comportamentos de enfrentamento à dor e sintomas afetivos, como a catastrofização da dor, nesses pacientes (Finan et al., 2010; Finan et al., 2011). Em um estudo recente, com pacientes espanhóis com FM, os portadores do genótipo Met/Met exibiram níveis significativamente mais elevados de fadiga autorrelatada que portadores heterozigotos (Val/Met) (Ferrera et al, 2021). Por outro lado, o genótipo Val/Val foi associado à disfunção na memória de trabalho em pacientes espanhóis com FM (Ferrera et al., 2020).

No que diz respeito à associação direta do polimorfismo COMT Val158Met (rs4680) com a suscetibilidade à FM, os dados são conflitantes. Alguns estudos foram capazes de demonstrar essa associação em pacientes com FM de diferentes origens étnicas (Gürsoy et al., 2003; Josep García-Fructuoso et al., 2006; Vargas-Alarcón et al., 2007; Cohen et al., 2009; Matsuda et al., 2010; Barbosa et al., 2012; Inanir et al., 2014), entretanto, outros, incluindo um estudo realizado com uma grande coorte nos Estados Unidos (Lee et al., 2018) não foram capazes de demonstrá-la (Vargas-Alarcón et al., 2007; Tander et al., 2008; Nicholl et al., 2010; Hatami et al., 2020). Outros polimorfismos que também ocorrem no gene COMT, rs6269 (ocorre na região promotora) e rs4818 (ocorre na região codificadora), foram associados à FM em um grupo de pacientes espanhóis, quando comparados a controles saudáveis; porém essa mesma associação não foi encontrada no grupo de pacientes mexicanos deste mesmo estudo (Vargas-Alarcón et al., 2007). COMT rs4818 também foi associado à FM em um grupo de pacientes coreanos com FM (Park et al., 2016a) e em um grupo de pacientes brasileiros com FM (Barbosa et al., 2012). COMT rs2097903 foi associado com um maior risco de suscetibilidade à fibromialgia em mulheres espanholas com FM (EstévezLópez et al., 2018b). A associação direta de polimorfismos da COMT com a suscetibilidade à FM, porém, parece ter relação com a origem étnica da população estudada (Vargas-Alarcón et al., 2007; Tammimäki \& Männistö, 2012; Lee et al., 2018).

\section{Receptores Adrenérgicos}

Os receptores adrenérgicos (AR) são membros da superfamília de receptores ligados à proteína $\mathrm{G}$ e desempenham um importante papel no sistema catecolaminérgico. Nesse sistema, enquanto a COMT age no metabolismo das catecolaminas, as degradando e inativando, os ARs são o alvo dessas moléculas, sendo a sua ativação dependente da ligação de uma catecolamina. São classificados amplamente como alfa ( $\alpha$ AR) e beta ( $\beta A R$ ) (Small et al., 2003). Um estudo, realizado em modelo animal, demonstrou que a baixa atividade da COMT leva a um aumento da sensibilidade à dor por meio da ativação de receptores adrenérgicos do tipo beta (Nackley et al., 2007).

ARs do tipo beta 2 ( $\beta 2 \mathrm{AR}$ ) são codificados pelo gene ADRB2 que em humanos está localizado no cromossomo 5q31q32 (Yang-Feng et al., 1990). Polimorfismos deste gene já foram associados a um aumento da gravidade do estado de dor em 
condições de dor crônica (Hocking et al., 2010). Os polimorfismos rs1042713 (Arg16Gly) e rs1042714 (Gln27Glu) são conhecidos por alterarem as funções do receptor, o tornando resistente à dessensibilização (Chong et al., 2000) e já tiveram sua associação com a FM investigada. Um estudo com haplótipos compostos por esses dois polimorfismos reportou o haplótipo mutante Gly/Glu como um fator de risco para a presença de FM em pacientes mexicanos com FM (Vargas-Alarcón et al., 2009). Outro estudo demonstrou uma frequência significativamente menor do genótipo heterozigoto (Arg/Gly) do ADRB2 rs1042713 (Arg16Gly) em pacientes com FM em comparação ao grupo controle e que ele também está associado a uma baixa significativa da qualidade do sono nesses pacientes. Nesse mesmo estudo genótipos do polimorfismo 1042713 também foram associados a uma diferença significativa da atividade do $\beta A R$ em pacientes com FM (Xiao et al., 2011). ARs do tipo alfa 1A ( $\alpha 1$ AAR) são codificados pelo gene ADRA1A que em humanos está localizado no cromossomo 8p21.2 (Schwinn et al., 1990; Hoehe et al., 1992). Polimorfismos nesse gene foram reportados em um estudo de associação com a FM. Em pacientes espanhóis o SNP rs1383914 foi associado à presença de FM e o SNP rs1048101 associado a uma maior severidade da FM avaliada por meio do FIQ. Estudo em pacientes mexicanos com FM associou o SNP rs574584 a uma maior severidade da FM também avaliada por meio do FIQ (Vargas-Alarcón et al., 2009). Os polimorfismos associados ao metabolismo das catecolaminas estão apresentados na Tabela 2.

Tabela 2. Polimorfismos em genes associados ao metabolismo das catecolaminas.

\begin{tabular}{|c|c|c|c|}
\hline Localização & Genótipo/Alelo & Associação & Referência \\
\hline \multicolumn{4}{|l|}{ COMT $(22 \mathrm{q} 11.21)$} \\
\hline \multirow[t]{19}{*}{ rs4680 (Val158Met) } & Met/Met & Aumento da sensibilidade à dor & Cohen et al., 2009 \\
\hline & & & Barbosa et al., 2012 \\
\hline & & & Martínez-Jauand et al., 2013 \\
\hline & Met/Met & Aumento da sensibilização central & Desmeules et al., 2014 \\
\hline & Met/Met & Agravamento de fatores psicológicos FM & Desmeules et al., 2012 \\
\hline & & (ansiedade, depressão, entre outros) & Fernández-de-las-Peñas et al., 2012 \\
\hline & & & Martínez-Jauand et al., 2013 \\
\hline & Met/Met & Baixa capacidade dos comportamentos de & Finan et al., 2010 \\
\hline & & $\begin{array}{l}\text { enfrentamento à dor e sintomas afetivos } \\
\text { (catastrofização da dor) }\end{array}$ & Finan et al., 2011 \\
\hline & Met/Met & $\begin{array}{l}\text { Níveis significativamente mais elevados de fadiga } \\
\text { autorrelatada }\end{array}$ & Ferrera et al, 2021 \\
\hline & $\mathrm{Val} / \mathrm{Val}$ & Disfunção na memória de trabalho & Ferrera et al., 2020 \\
\hline & NA & Suscetibilidade à FM & Gürsoy et al., 2003 \\
\hline & & & Josep García-Fructuoso et al., 2006 \\
\hline & & & Vargas-Alarcón et al., 2007 \\
\hline & & & Cohen et al., 2009 \\
\hline & & & Matsuda et al., 2010 \\
\hline & & & Barbosa et al., 2012 \\
\hline & & & Inanir et al., 2014 \\
\hline & & & Vargas-Alarcón et al., 2007 \\
\hline rs4818 & NA & Suscetibilidade à FM & Barbosa et al., 2012 \\
\hline & & & Park et al., 2016 \\
\hline rs6269 & NA & Suscetibilidade à FM & Vargas-Alarcón et al., 2007 \\
\hline rs 2097903 & NA & Risco aumentado de desenvolver FM & Estévez-López et al., 2018b \\
\hline \multicolumn{4}{|l|}{$A D R B 2(5 q 31-q 32)$} \\
\hline $\begin{array}{l}\text { rs1042713 (Arg16Gly) e } \\
\text { rs1042714 (Gln27Glu) }\end{array}$ & Haplótipo Gly/Glu & Fator de risco para a presença de FM & Vargas-Alarcón et al., 2009 \\
\hline \multirow[t]{3}{*}{ rs1042713 (Arg16Gly) } & Arg/Gly & Frequência significativamente menor & Xiao et al., 2011 \\
\hline & & Baixa significativa da qualidade do sono & \\
\hline & NA & $\begin{array}{l}\text { Diferença significativa da atividade do receptor } \\
\text { beta adrenérgico entre os genótipos }\end{array}$ & Xiao et al., 2011 \\
\hline \multicolumn{4}{|l|}{$A D R A 1 A(8 \mathrm{p} 21.2)$} \\
\hline rs1383914 & NA & Associado à FM & Vargas-Alarcón et al., 2009 \\
\hline rs1048101 & NA & Maior severidade da FM & Vargas-Alarcón et al., 2009 \\
\hline rs574584 & NA & Maior severidade da FM & Vargas-Alarcón et al., 2009 \\
\hline
\end{tabular}

NA, não se aplica. Fonte: Autores. 


\section{Mecanismos periféricos}

Evidências de substâncias pró-inflamatórias no soro de pacientes com FM (Wang et al., 2008) reforçam a teoria do envolvimento de mecanismos inflamatórios na fisiopatologia da FM e de que eles podem influenciar a excitabilidade das vias nociceptivas (Sarzi-puttini et al., 2020). Polimorfismos relacionados à via inflamatória têm sido reportados em estudos de associação com a FM. A interleucina 4 (IL-4) é uma das principais citocinas anti-inflamatórias e está envolvida na regulação da transcrição dos receptores $\mathrm{Mu}(\mu)$ e Delta $(\delta)$ opioides. Alterações nesse sistema podem ter influências na percepção da dor e na resistência a opioides, observada com frequência em pacientes com dor crônica generalizada (Uçeyler et al., 2006). O polimorfismo 70 bp VNTR do gene IL-4 (cromossomo 5q31.1) foi associado com uma suscetibilidade à FM (Yigit et al., 2013). Outro polimorfismo associado a essa via é o rs224222 (R202Q) do gene da febre mediterrânea (MEFV), localizado no cromossomo 16p13.3 em humanos (Chae et al., 2000). Esse gene codifica a pirina, uma proteína que funciona como reguladora da imunidade inata (Masters et al., 2016). O MEFV rs224222 foi associado à FM e a um aumento da fadiga matinal nos pacientes com FM (Karakus et al., 2012).

A enzima conversora da angiotensina (ACE), codificada pelo gene ACE, que em humanos está localizado no cromossomo 17q23.3, é um importante componente do sistema renina-angiotensina envolvido na regulação da pressão arterial e no metabolismo da substância neuropeptídica $\mathrm{P}$ e tem sido associado à depressão e distúrbios cardiovasculares (Bondy, 2003). O polimorfismo ACE rs1799752 foi associado com uma suscetibilidade à FM (Inanir et al., 2015) e ACE rs4646994 associado à síndrome da perna inquieta em pacientes com FM (Khalil et al. 2020). O receptor mineralocorticóide (MR; $\mathrm{NR} 3 \mathrm{C} 2$, receptor nuclear subfamília 3, grupo C, membro 2), funciona como um fator de transcrição dependente de ligante que medeia os efeitos da aldosterona em uma variedade de tecidos alvo (Zennaro et al., 2001), no cérebro, atua na regulação do estresse e processos cognitivos e desempenha importante papel no controle da atividade do eixo HPA (hipotálamo-pituitáriaadrenal) circadiano e relacionada ao estresse (DeRijk et al., 2006; Macedo et al., 2008). Codificado pelo gene NR3C2 (cromossomo 4q31.23), possui um polimorfismo (rs5522 - I180V) que foi reportado em um estudo com pacientes com FM. Nesse estudo o alelo mutante Val foi encontrado com mais frequência nos pacientes com FM do que no grupo controle (Macedo et al., 2008). Além de estar associado a uma leve perda da função do receptor (DeRijk et al., 2006). A endotelina-1 (ET-1) é um peptídeo com potente função vasoconstritora, produzido por células endoteliais vasculares (Inoue et al., 1989), codificado pelo gene EDN1 que em humanos está localizado no cromossomo 6p24.1 (Pages et al., 1993). Níveis elevados de ET-1 foram encontrados no plasma e soro de pacientes afetados por condições de dor crônica (Pache et al., 2002; KuryliszynMoskal et al., 2006). O polimorfismo rs 1800541 deste gene resulta na alteração de uma timina por uma guanina na posição 1370 desse gene (T1370G) e, em um estudo, teve o genótipo TG e o alelo G associados à FM e a níveis plasmáticos de ET-1 mais elevados em pacientes com FM em comparação com controles saudáveis (Nah et al., 2017).

A metilenotetraidrofolato redutase (MTHFR) é uma enzima chave do metabolismo do folato, codificada pelo gene MTHFR, localizado no cromossomo 1p36.22 em humanos (Gaughan et al., 2000). Polimorfismos nesse gene podem levar a uma redução da atividade da MTHFR, causando comprometimento de mecanismos de grande importância em processos cerebrais como a metilação e levando à deficiência de folato, que tem sido associada a diversas doenças psiquiátricas como, esquizofrenia, transtorno bipolar, depressão, autismo e transtorno do déficit de atenção com hiperatividade (Klengel et al., 2014; Wan et al., 2018). Também foram associados a doenças vasculares relacionadas ao envelhecimento (Schmechel \& Edwards, 2012). Estudo demonstraram uma associação entre o polimorfismo MTHFR rs1801133 (C677T) e características clínicas da FM, como aumento na sensação de rigidez e olho seco (Inanir et al., 2015) e a uma influência da prática de exercícios físicos na sensação de fadiga em pacientes com FM (Estévez-López et al., 2021a). 


\section{Neuroplasticidade}

O fator neurotrófico derivado do cérebro (BDNF) é a principal e mais abundante neurotrofina do CNS, expresso no hipocampo, amígdala, cerebelo e neocórtex (Shimizu et al., 2003), é mediador de muitos processos no cérebro de mamíferos, incluindo a formação e plasticidade de sinapses, crescimento e diferenciação neuronal e funções cognitivas superiores (Park \& Poo, 2013). Membro da família do fator de crescimento do nervo, é codificado pelo gene BDNF, que em humanos está localizado no cromossomo 11p14.1 (Hanson et al., 1992). Evidências sugerem que indivíduos acometidos por sintomas psiquiátricos, como a desordem depressiva maior (MDD), possuem níveis séricos reduzidos de BDNF (Shimizu et al., 2003). O gene BDNF possui um SNP (rs6265; c.196G > A), que resulta na alteração de uma valina para uma metionina no resíduo 66 do aminoácido (Val66Met) que afeta a distribuição intracelular, empacotamento e liberação do BDNF (Egan et al., 2003), e têm sido associado a um agravamento de sintomas de ansiedade (Lang et al., 2005) e depressão (Zhao et al., 2018), sintomas frequentemente apresentados por pacientes com FM (Clauw, 2014; Sarzi-Puttini et al., 2020). Em mulheres brasileiras com FM, o alelo Val desse polimorfismo foi mais frequente em comparação ao grupo controle. Nesse mesmo grupo, o genótipo $\mathrm{Val} / \mathrm{Val}$ foi associado a um aumento nos pensamentos catastrofistas de dor em comparação ao genótipo Val/Met, demonstrando uma associação do polimorfismo BDNF Val66Met com a catastrofização da dor na FM (da Silveira Alves et al., 2020). O genótipo Val/Val também foi associado a maiores níveis séricos de proteína $\mathrm{C}$ reativa de alta sensibilidade (marcador de processo inflamatório) e a um índice de massa corporal (IMC) médio mais alto em pacientes com FM em comparação aos pacientes com o genótipo heterozigoto Val/Met (Xiao et al., 2012).

Outros polimorfismos do BDNF já foram reportados em estudos com pacientes com FM. Os SNPs rs2049046 (A>T) e rs7124442 (A>G) foram associados com um maior IMC e maiores escores de ansiedade em pacientes com FM com relação ao grupo controle. Além disso, pacientes portadores dos genótipos AA e AT do SNP rs2049046 apresentaram maiores escores de ansiedade em comparação aos com o genótipo TT (Nugraha et al., 2020). Já um estudo multicêntrico com indivíduos coreanos encontrou diferenças significativas nas frequências alélicas e genotípicas do BDNF rs11030104 entre os grupos de pacientes com FM e controle, sendo que no grupo de pacientes com FM o alelo $\mathrm{G}$ foi negativamente associado com a presença da FM em comparação ao alelo A. O polimorfismo BDNF rs12273539, também avaliado nesse estudo, teve o genótipo homozigoto TT associado a uma suscetibilidade à FM. Outros polimorfismos avaliados nessa mesma população não estão associados diretamente a uma suscetibilidade à FM, porém contribuem para sintomas específicos da doença, como o genótipo CG BDNF rs11030102 que foi associado a sintomas mais graves de fadiga e ansiedade em comparação aos demais genótipos (CC e GG). Sintomas mais graves de ansiedade nos pacientes com FM desse estudo também foram associados aos polimorfismos BDNF rs11030101 e rs10835210 (Park et al., 2018).

\section{Ciclo celular}

O polimorfismo rs6860 está localizado na região 3'-UTR do gene CHMP1A, que em humanos situa-se no cromossomo 16q24.3 (Scott et al., 1996) e codifica a proteína multivesicular corporal carregada 1A (CHMP1A). O polimorfismo ocorre em uma região que contém locais de ligação para proteínas regulatórias e microRNAs que podem afetar a expressão desse gene (Estévez-López et al., 2018a). CHMP1A pertence à família da proteína modificadora da cromatina e são fundamentais para a formação de corpos multivesiculares endocíticos (MVBs) e na regulação da progressão do ciclo celular (Tsang et al., 2006). O genótipo TT e o alelo T do CHMP1A rs6860 foram associados a uma suscetibilidade à fibromialgia em mulheres do sul da Espanha (Estévez-López et al., 2018a) e recentemente esse polimorfismo foi associado a um aumento do comportamento sedentário, uma sub-escala na avaliação de dor corporal, em mulheres com FM (Estévez-López et al., 2021b). Disfunções mitocondriais contribuem para a percepção da dor e condições de dor crônica (Sui et al., 2013; Flatters, 2015) e esse é o principal sintoma que acomete indivíduos com FM. O alelo C do polimorfismo rs28358579 (m.2352T> C), que ocorre 
no gene mitocondrial MT-RNR2, foi associado ao risco aumentado de desenvolver FM (van Tilburg et al., 2020).

\section{Neurotransmissão}

O alelo 3 do polimorfismo localizado na região promotora VNTR (número variável de repetições tandem da sigla em inglês) do gene MAO-A (cromossomo Xp11.4-p11.23) foi reportado como um fator de risco para o desenvolvimento da FM e associado a um agravamento dos sintomas (avaliados pelo FIQ) em pacientes com FM (Gürsoy et al., 2008). A monoamina oxidase A (MAO-A) é uma enzima que participa da oxidação de neurotransmissores e aminas, essenciais para um estado mental normal, tendo como substratos, especialmente, os neurotransmissores serotonina, norepinefrina e dopamina (Chen et al., 2004). A proteína associada ao sinaptossoma de $25 \mathrm{kDa}$ (SNAP-25) também desempenha um papel importante na neurotransmissão, mediando a fusão da vesícula sináptica com a membrana plasmática e também modulando a neurotransmissão por meio do controle dos canais de cálcio dependentes de voltagem e da concentração pré-sináptica de íons de cálcio. Polimorfismos no gene SNAP-25 (cromossomo 20p12.2) podem resultar em um bloqueio completo da transmissão sináptica (Pozzi et al., 2019) e têm sido associados ao desenvolvimento de distúrbios neuropsiquiátricos como transtorno bipolar, Alzheimer, esquizofrenia, transtorno do déficit de atenção com hiperatividade, entre outros (Najera et al., 2019). O polimorfismo SNAP-25 rs1051312 foi associado à FM e a um agravamento dos sintomas de dor e depressão em pacientes com FM (Balkarli et al., 2014).

\section{Outros}

A apolipoproteína E (APOE) é uma glicoproteína codificada pelo gene APOE (cromossomo 19q13.32) (Lusis et al., 1986), que tem sido associado a diversas doenças como, Alzheimer, Parkinson, aterosclerose, artrite reumatoide, transtorno bipolar, esquizofrenia, entre outros (Mortensen \& Høgh, 2001; Becker et al., 2010). O alelo E4 desse gene foi associado ao desenvolvimento da FM pós-traumática. Entre os indivíduos com histórico de acidente com veículo motorizado, com pelo menos uma cópia do alelo E4, o risco de ser diagnosticado com FM foi significativamente maior que indivíduos que não possuíam esse alelo (Reeser et al., 2011). Enquanto o alelo E2 parece conferir um papel protetor ao agravamento do estresse em mulheres com FM (Becker et al., 2010).

Estudos com GWAS trouxeram contribuições a respeito de possíveis componentes genéticos envolvidos na fisiopatologia da FM. Um estudo que analisou a associação da FM com um painel de mais de 350 genes envolvidos nas vias de nocicepção, inflamação e humor, encontrou os polimorfismos: GABRB3 rs4906902, TAAR1 rs8192619, GRIA4 rs642544, RGS4 rs10799897 e CNR1 rs6454674 associados à via nociceptiva em pacientes com FM e GBP1 rs7911 associado à via inflamatória nesses pacientes (Smith et al., 2012). Em outro estudo, nenhum SNP atingiu o limite de associação GWAS, porém na análise da variante do número de cópias (CNV, Copy Number Variation) por hibridização genômica comparativa de matriz (aCGH, Microarray-based Comparative Genomic Hybridization) foi demonstrado que uma deleção intrônica no gene NRXN3 está associada à FM e a baixos níveis de comorbidades em mulheres com FM (Docampo et al., 2014). Os polimorfismos associados a mecanismos periféricos, neuroplasticidade, ciclo celular, neurotransmissão, entre outros, são apresentados na Tabela 3. 
Tabela 3. Polimorfismos em genes associados a outras vias.

\begin{tabular}{|c|c|c|c|}
\hline Localização & Genótipo/Alelo & Associação & Referência \\
\hline $\begin{array}{l}L-4(\mathbf{5 q 3 1 . 1}) \\
70 \text { bp VNTR }\end{array}$ & NA & Suscetibilidade à FM & Yigit et al., 2013 \\
\hline $\begin{array}{l}\text { MEFV }(\mathbf{1 6 p 1 3 . 3}) \\
\quad \text { rs224222 (R202Q) }\end{array}$ & NA & $\begin{array}{l}\text { Associado à FM } \\
\text { Aumento da fadiga matinal }\end{array}$ & Karakus et al., 2012 \\
\hline $\begin{array}{r}\text { ACE } \\
\mathbf{( 1 7 q 2 3 . 3}) \\
\text { rs1799752 } \\
\text { rs } 4646994\end{array}$ & $\begin{array}{l}\text { NA } \\
\text { NA }\end{array}$ & $\begin{array}{l}\text { Suscetibilidade à FM } \\
\text { Síndrome da perna inquieta }\end{array}$ & $\begin{array}{l}\text { Inanir et al., } 2015 \\
\text { Khalil et al. } 2020\end{array}$ \\
\hline $\begin{array}{l}N R 3 C 2(\mathbf{4 q 3 1 . 2 3}) \\
\text { rs5522 (I180V) }\end{array}$ & Alelo Val & Associado à FM & Macedo et al., 2008 \\
\hline $\begin{array}{l}\boldsymbol{E} D N 1(\mathbf{6 p 2 4 . 1}) \\
\quad \text { rs1800541 (T1370G) }\end{array}$ & $\begin{array}{l}\text { Genótipo TG } \\
\text { Alelo G }\end{array}$ & $\begin{array}{l}\text { Associados à FM } \\
\text { Níveis plasmáticos de ET-1 mais elevados }\end{array}$ & Nah et al., 2017 \\
\hline $\begin{array}{l}\text { MTHFR }(\mathbf{1 p 3 6 . 2 2}) \\
\text { rs1801133 (C677T) }\end{array}$ & NA & $\begin{array}{l}\text { Aumento na sensação de rigidez } \\
\text { Olho seco } \\
\text { Fadiga }\end{array}$ & $\begin{array}{l}\text { Inanir et al., } 2015 \\
\text { Estévez-López et al., 2021a }\end{array}$ \\
\hline $\begin{array}{l}\text { BDNF (11p14.1) } \\
\quad \text { rs6265 (Val66Met) }\end{array}$ & $\begin{array}{l}\text { Alelo Val } \\
\text { Val/Val } \\
\text { Val/Val }\end{array}$ & $\begin{array}{l}\text { Associado à FM } \\
\text { Aumento nos pensamentos catastrofistas de dor } \\
\text { Maiores níveis séricos de proteína C reativa de alta } \\
\text { sensibilidade (marcador de processo inflamatório) }\end{array}$ & $\begin{array}{l}\text { da Silveira Alves et al., } 2020 \\
\text { da Silveira Alves et al., } 2020 \\
\text { Xiao et al., } 2012\end{array}$ \\
\hline rs2049046 (A>T) & $\begin{array}{l}\text { Val/Val } \\
\text { NA } \\
\text { A/A e A/T }\end{array}$ & $\begin{array}{l}\text { IMC médio mais alto } \\
\text { Maior IMC } \\
\text { Maiores escores de ansiedade } \\
\text { Maiores escores de ansiedade }\end{array}$ & $\begin{array}{l}\text { Xiao et al., } 2012 \\
\text { Nugraha et al., } 2020\end{array}$ \\
\hline rs7124442 (A>G) & NA & $\begin{array}{l}\text { Maior IMC } \\
\text { Maiores escores de ansiedade }\end{array}$ & Nugraha et al., 2020 \\
\hline $\begin{array}{l}\text { rs11030104 } \\
\text { rs12273539 } \\
\text { rs11030102 } \\
\text { rs11030101 } \\
\text { rs10835210 }\end{array}$ & $\begin{array}{l}\text { Alelo G } \\
\text { T/T } \\
\text { C/G } \\
\text { NA } \\
\text { NA }\end{array}$ & $\begin{array}{l}\text { Associado à FM } \\
\text { Suscetibilidade à FM } \\
\text { Sintomas mais graves de fadiga e ansiedade } \\
\text { Sintomas mais graves de ansiedade } \\
\text { Sintomas mais graves de ansiedade }\end{array}$ & $\begin{array}{l}\text { Park et al., } 2018 \\
\text { Park et al., } 2018 \\
\text { Park et al., } 2018 \\
\text { Park et al., } 2018 \\
\text { Park et al., } 2018\end{array}$ \\
\hline $\begin{array}{c}\text { CHMP1A (16q24.3) } \\
\text { rs } 6860\end{array}$ & $\begin{array}{l}\mathrm{T} / \mathrm{T} \\
\text { Alelo T } \\
\text { NA }\end{array}$ & $\begin{array}{l}\text { Suscetibilidade à fibromialgia } \\
\text { Aumento do comportamento sedentário }\end{array}$ & $\begin{array}{l}\text { Estévez-López et al., 2018a } \\
\text { Estévez-López et al., 2021b }\end{array}$ \\
\hline $\begin{array}{l}\text { MT-RNR2 (mitocôndria) } \\
\quad \text { rs28358579 (m.2352T>C) }\end{array}$ & Alelo C & Risco aumentado de desenvolver FM & van Tilburg et al., 2020 \\
\hline $\begin{array}{r}\text { MAO-A }(\mathrm{Xp11.4-p11.23)} \\
\text { VNTR - promotora }\end{array}$ & Alelo 3 & $\begin{array}{l}\text { Fator de risco para o desenvolvimento da FM } \\
\text { Agravamento dos sintomas }\end{array}$ & Gürsoy et al., 2008 \\
\hline $\begin{array}{c}\text { SNAP-25 (20p12.2) } \\
\text { rs1051312 }\end{array}$ & NA & $\begin{array}{l}\text { Associado à FM } \\
\text { Agravamento dos sintomas de dor e depressão }\end{array}$ & Balkarli et al., 2014 \\
\hline$A P O E(19 q 13.32)$ & $\begin{array}{l}\text { Alelo E4 } \\
\text { Alelo E2 }\end{array}$ & $\begin{array}{l}\text { Desenvolvimento da FM pós-traumática } \\
\text { Papel protetor ao agravamento do estresse }\end{array}$ & $\begin{array}{l}\text { Reeser et al., } 2011 \\
\text { Becker et al., } 2010\end{array}$ \\
\hline $\begin{array}{l}G W A S \\
\text { GABRB3 rs4906902 } \\
\text { TAAR1 rs8192619 } \\
\text { GRIA4 rs642544 } \\
\text { RGS4 rs10799897 } \\
\text { CNR1 rs6454674 }\end{array}$ & NA & Associados à via nociceptiva em pacientes com FM & Smith et al., 2012 \\
\hline GBP1 rs7911 & & Associado à via inflamatória em pacientes com FM & Smith et al., 2012 \\
\hline $\begin{array}{l}\text { CNV por aCGH } \\
N R X N 3\end{array}$ & Deleção intrônica & $\begin{array}{l}\text { Associada à FM } \\
\text { Baixos níveis de comorbidades }\end{array}$ & Docampo et al., 2014 \\
\hline
\end{tabular}

aCGH, Microarray-based Comparative Genomic Hybridization. CNV, Copy Number Variation. GWAS, Genome Wide Association Studies. NA, não se aplica. VNTR, Variable number of tandem repeats. Fonte: Autores. 


\section{Conclusão}

Nas últimas décadas diversas pesquisas permitiram avanços consideráveis na compreensão da fisiopatologia da FM, especialmente no que diz respeito ao processamento da dor. Mais recentemente, o estudo dos principais fatores genéticos envolvidos nessa complexa condição tem emergido, porém, ainda que muitos polimorfismos genéticos tenham sido reportados como potenciais candidatos, boa parte dos estudos possuem baixo número amostral, o que torna algumas associações passíveis de confirmação através de metanálises subsequentes. Além disso, a maioria dos estudos avalia o efeito individual dos polimorfismos nos pacientes com FM, mesmo os que se propõem a avaliar mais de um polimorfismo. Entretanto, é possível que haja uma interação entre polimorfismos e que essa interação contribua para a variabilidade individual do conjunto sintomatológico que acomete os pacientes com essa condição. Indivíduos portadores de um mesmo genótipo de determinado polimorfismo apresentam, ainda assim, variação de sintomas e isso pode estar relacionado ao fato desse polimorfismo estar interagindo com outros. Diferentes polimorfismos, de diferentes genes, podem sofrer influência de outros, tanto negativa como positivamente, podendo haver uma compensação ou até mesmo o agravo de algum sintoma em decorrência dessa interação. Pacientes mais resilientes, por exemplo, apresentam menos comportamento de dor, melhores estilos de enfrentamento e menos tendência de catastrofização que pacientes não resilientes com dor crônica (Karoly \& Ruehlman, 2006). Em um estudo com pacientes com FM, interações significativas entre polimorfismos funcionais foram reportadas para os genes OPRM1(rs1799971) x 5-HTT (rs25531) e OPRM1 (rs1799971) x 5-HT1A (rs6296), sugerindo que há efeitos conjuntos dos mecanismos opioides e serotoninérgicos na regulação da inibição da dor endógena (Tour et al., 2017).

Ademais às evidências do envolvimento de fatores genéticos, estudos mais recentes têm sugerido que fatores ambientais, especialmente o trauma infantil, parecem exercer um importante papel no surgimento e desenvolvimento da FM, através da interação gene-ambiente, a qual se dá por meio de mecanismos epigenéticos. Estes, por sua vez, podem modular a função do genoma e o fenótipo por meio de modificações covalentes de histonas, metilação do DNA ou RNAs não codificadores, sem que a sequência do DNA seja alterada (Low \& Schweinhardt, 2012; Szyf \& Bick 2013). Alguns estudos (em grande parte estudos piloto ou com pequeno número amostral) foram conduzidos com pacientes com FM e evidências sugerem uma prevalência da influência de padrões (hipo ou hiper) de metilação do DNA nesse grupo, em genes implicados em vias reparo de DNA, processos relacionados ao sistema imunológico, metabolismo relacionado a lipídios, transporte de membrana, sensibilização central, depressão, diferenciação neuronal, desenvolvimento do sistema esquelético e compactação da cromatina (Menzies et al., 2013; Ciampi de Andrade et al., 2017; Gerra et al., 2020; Gerra et al., 2021). Em um estudo com um pequeno grupo misto, composto por pacientes com FM e síndrome da fadiga crônica, resultados preliminares demonstraram que nesse grupo a metilação do DNA do BDNF foi menor em comparação aos indivíduos do grupo controle e que essa metilação é mediada pelo polimorfismo BDNF Val66Met, sugerindo que sua influência na expressão do BDNF possa se dar através desse mecanismo epigenético (Polli et al., 2020). RNAs não codificantes também foram encontrados em pacientes com FM, associados a processos relacionados ao sistema imunológico (Dolcino et al., 2020). Diferentes perfis de expressão de microRNAs entre os mais diversos tecidos, também foram encontrados nesses pacientes (D'Agnelli et al., 2019).

Sabe-se também que determinadas práticas podem funcionar como fatores de proteção à predisposição genética, como exercícios físicos melhorarem o prognóstico em portadores de polimorfismos negativamente associados aos diversos sintomas da FM. Um exemplo é um estudo de GWAS, que avaliou o papel da suscetibilidade genética e a interação gene-atividade física à fadiga em mulheres com FM. De fato, a prática de exercícios físicos influenciou na diminuição da sensação de fadiga nas pacientes com FM portadoras dos polimorfismos SCN9A rs4453709, rs4597545 e rs7607967 e MTHFR rs1801133 (C677T) (Estévez-López et al., 2021a). Neste sentido, é desejável que os novos estudos sejam realizados com amostras maiores e façam uso das diversas novas tecnologias de análise genética, tais como GWAS, sequenciamento de nova geração, estudos de microRNAs, ferramentas de análise epigenética (p.ex. metilação de DNA e alterações da cromatina), visando uma abordagem 
para integradora e ampla para o avanço do conhecimento das bases genéticas da FM. O desenvolvimento de painéis genéticos e epigenéticos com os principais fatores associados à FM parece ser, no futuro, uma interessante estratégia na compreensão da particularidade sintomatológica de cada paciente que, por consequência, direcionaria na tomada de decisão sobre as melhores estratégias terapêuticas para esses indivíduos.

\section{Agradecimentos}

O presente trabalho foi realizado com apoio do Conselho Nacional de Desenvolvimento Científico e Tecnológico (CNPq) e da Coordenação de Aperfeiçoamento de Pessoal de Nível Superior - Brasil (CAPES) - Código de Financiamento 001 .

\section{Referências}

Ablin, J. N., \& Buskila, D. (2014). Predicting fibromyalgia, a narrative review: are we better than fools and children?. European journal of pain (London, England), 18(8), 1060-1066. https://doi.org/10.1002/j.1532-2149.2014.00481.x

Ablin, J. N., \& Buskila, D. (2015). Update on the genetics of the fibromyalgia syndrome. Best practice \& research. Clinical rheumatology, 29(1), 20-28. https://doi.org/10.1016/j.berh.2015.04.018

Affleck, G., Urrows, S., Tennen, H., Higgins, P., \& Abeles, M. (1996). Sequential daily relations of sleep, pain intensity, and attention to pain among women with fibromyalgia. Pain, 68(2-3), 363-368. https://doi.org/10.1016/s0304-3959(96)03226-5

Araya-Quintanilla, F., Gutiérrez-Espinoza, H., Muñoz-Yánez, M. J., Cavero-Redondo, I., Álvarez-Bueno, C., \& Martinez-Vizcaíno, V. (2020). Effectiveness of a multicomponent treatment versus conventional treatment in patients with fibromyalgia: Study protocol. Medicine, 99(4), e18833. https://doi.org/10.1097/MD.0000000000018833

Arnold, L. M., Hudson, J. I., Hess, E. V., Ware, A. E., Fritz, D. A., Auchenbach, M. B., Starck, L. O., \& Keck, P. E., Jr (2004). Family study of fibromyalgia. Arthritis and rheumatism, 50(3), 944-952. https://doi.org/10.1002/art.20042

Bair, M. J., Robinson, R. L., Katon, W., \& Kroenke, K. (2003). Depression and pain comorbidity: a literature review. Archives of internal medicine, 163(20), 2433-2445. https://doi.org/10.1001/archinte.163.20.2433

Balkarli, A., Sengül, C., Tepeli, E., Balkarli, H., \& Cobankara, V. (2014). Synaptosomal-associated protein 25 (Snap-25) gene polymorphism frequency in fibromyalgia syndrome and relationship with clinical symptoms. BMC musculoskeletal disorders, 15, 191. https://doi.org/10.1186/1471-2474-15-191

Baraniuk, J. N., Whalen, G., Cunningham, J., \& Clauw, D. J. (2004). Cerebrospinal fluid levels of opioid peptides in fibromyalgia and chronic low back pain. BMC musculoskeletal disorders, 5, 48. https://doi.org/10.1186/1471-2474-5-48

Barbosa, F. R., Matsuda, J. B., Mazucato, M., de Castro França, S., Zingaretti, S. M., da Silva, L. M., Martinez-Rossi, N. M., Júnior, M. F., Marins, M., \& Fachin, A. L. (2012). Influence of catechol-O-methyltransferase (COMT) gene polymorphisms in pain sensibility of Brazilian fibromialgia patients. Rheumatology international, 32(2), 427-430. https://doi.org/10.1007/s00296-010-1659-z

Becker, R. M., da Silva, V. K., Machado, F., dos Santos, A. F., Meireles, D. C., Mergener, M., dos Santos, G. A., \& de Andrade, F. M. (2010). Association between environmental quality, stress and APOE gene variation in fibromyalgia susceptibility determination. Revista brasileira de reumatologia, 50(6), 617624. https://doi.org/10.1590/S0482-50042010000600003

Bennett, R. M., Friend, R., Jones, K. D., Ward, R., Han, B. K., \& Ross, R. L. (2009). The Revised Fibromyalgia Impact Questionnaire (FIQR): validation and psychometric properties. Arthritis research \& therapy, 11(4), R120. https://doi.org/10.1186/ar2783

Berger, A., Dukes, E., Martin, S., Edelsberg, J., \& Oster, G. (2007). Characteristics and healthcare costs of patients with fibromyalgia syndrome. International journal of clinical practice, 61(9), 1498-1508. https://doi.org/10.1111/j.1742-1241.2007.01480.x

Bilge, U., Sari, Y. E., Balcioglu, H., Yasar Bilge, N. S., Kasifoglu, T., Kayhan, M., \& Unluoglu, I. (2018). Prevalence of comorbid diseases in patients with fibromyalgia: A retrospective cross-sectional study. JPMA. The Journal of the Pakistan Medical Association, 68(5), 729-732.

Bond, C., LaForge, K. S., Tian, M., Melia, D., Zhang, S., Borg, L., Gong, J., Schluger, J., Strong, J. A., Leal, S. M., Tischfield, J. A., Kreek, M. J., \& Yu, L. (1998). Single-nucleotide polymorphism in the human mu opioid receptor gene alters beta-endorphin binding and activity: possible implications for opiate addiction. Proceedings of the National Academy of Sciences of the United States of America, 95(16), 9608-9613. https://doi.org/10.1073/pnas.95.16.9608

Bondy B. (2003). Common genetic risk factors for psychiatric and simatic disorders. Dialogues in clinical neuroscience, 5(2), 129-138. https://doi.org/10.31887/DCNS.2003.5.2/bbondy

Bondy, B., Spaeth, M., Offenbaecher, M., Glatzeder, K., Stratz, T., Schwarz, M., de Jonge, S., Krüger, M., Engel, R. R., Färber, L., Pongratz, D. E., \& Ackenheil, M. (1999). The T102C polymorphism of the 5-HT2A-receptor gene in fibromyalgia. Neurobiology of disease, 6(5), 433-439. https://doi.org/10.1006/nbdi.1999.0262

Boomershine, C. S., \& Crofford, L. J. (2009). A symptom-based approach to pharmacologic management of fibromyalgia. Nature reviews. Rheumatology, 5(4), 191-199. https://doi.org/10.1038/nrrheum.2009.25 
Borchers, A. T., \& Gershwin, M. E. (2015). Fibromyalgia: A Critical and Comprehensive Review. Clinical reviews in allergy \& immunology, 49(2), 100-151. https://doi.org/10.1007/s12016-015-8509-4

Burckhardt, C. S., Clark, S. R., \& Bennett, R. M. (1991). The fibromyalgia impact questionnaire: development and validation. The Journal of rheumatology, 18(5), 728-733.

Buskila, D., Cohen, H., Neumann, L., \& Ebstein, R. P. (2004). An association between fibromyalgia and the dopamine D4 receptor exon III repeat polymorphism and relationship to novelty seeking personality traits. Molecular psychiatry, 9(8), 730-731. https://doi.org/10.1038/sj.mp.4001506

Cabo-Meseguer, A., Cerdá-Olmedo, G., \& Trillo-Mata, J. L. (2017). Fibromyalgia: Prevalence, epidemiologic profiles and economic costs. Fibromialgia: prevalencia, perfiles epidemiológicos y costes económicos. Medicina clinica, 149(10), 441-448. https://doi.org/10.1016/j.medcli.2017.06.008

Carville, S. F., Arendt-Nielsen, L., Bliddal, H., Blotman, F., Branco, J. C., Buskila, D., Da Silva, J. A., Danneskiold-Samsøe, B., Dincer, F., Henriksson, C., Henriksson, K. G., Kosek, E., Longley, K., McCarthy, G. M., Perrot, S., Puszczewicz, M., Sarzi-Puttini, P., Silman, A., Späth, M., Choy, E. H., ... EULAR (2008). EULAR evidence-based recommendations for the management of fibromyalgia syndrome. Annals of the rheumatic diseases, 67(4), 536-541. https://doi.org/10.1136/ard.2007.071522

Chae, J. J., Centola, M., Aksentijevich, I., Dutra, A., Tran, M., Wood, G., Nagaraju, K., Kingma, D. W., Liu, P. P., \& Kastner, D. L. (2000). Isolation, genomic organization, and expression analysis of the mouse and rat homologs of MEFV, the gene for familial mediterranean fever. Mammalian genome : official journal of the International Mammalian Genome Society, 11(6), 428-435. https://doi.org/10.1007/s003350010082

Chang, F. M., Kidd, J. R., Livak, K. J., Pakstis, A. J., \& Kidd, K. K. (1996). The world-wide distribution of allele frequencies at the human dopamine D4 receptor locus. Human genetics, 98(1), 91-101. https://doi.org/10.1007/s004390050166

Chen, J., Lipska, B. K., Halim, N., Ma, Q. D., Matsumoto, M., Melhem, S., Kolachana, B. S., Hyde, T. M., Herman, M. M., Apud, J., Egan, M. F., Kleinman, J. E., \& Weinberger, D. R. (2004). Functional analysis of genetic variation in catechol-O-methyltransferase (COMT): effects on mRNA, protein, and enzyme activity in postmortem human brain. American journal of human genetics, 75(5), 807-821. https://doi.org/10.1086/425589

Chinn, S., Caldwell, W., \& Gritsenko, K. (2016). Fibromyalgia Pathogenesis and Treatment Options Update. Current pain and headache reports, 20(4), 25. https://doi.org/10.1007/s11916-016-0556-x

Chong, L. K., Chowdry, J., Ghahramani, P., \& Peachell, P. T. (2000). Influence of genetic polymorphisms in the beta2-adrenoceptor on desensitization in human lung mast cells. Pharmacogenetics, 10(2), 153-162. https://doi.org/10.1097/00008571-200003000-00007

Ciampi de Andrade, D., Maschietto, M., Galhardoni, R., Gouveia, G., Chile, T., Victorino Krepischi, A. C., Dale, C. S., Brunoni, A. R., Parravano, D. C., Cueva Moscoso, A. S., Raicher, I., Kaziyama, H., Teixeira, M. J., \& Brentani, H. P. (2017). Epigenetics insights into chronic pain: DNA hypomethylation in fibromyalgia-a controlled pilot-study. Pain, 158(8), 1473-1480. https://doi.org/10.1097/j.pain.0000000000000932

Clauw D. J. (2014). Fibromyalgia: a clinical review. JAMA, 311(15), 1547-1555. https://doi.org/10.1001/jama.2014.3266

Cohen, H., Buskila, D., Neumann, L., \& Ebstein, R. P. (2002). Confirmation of an association between fibromyalgia and serotonin transporter promoter region (5- HTTLPR) polymorphism, and relationship to anxiety-related personality traits. Arthritis and rheumatism, 46(3), 845-847. https://doi.org/10.1002/art.10103

Cohen, H., Neumann, L., Glazer, Y., Ebstein, R. P., \& Buskila, D. (2009). The relationship between a common catechol-O-methyltransferase (COMT) polymorphism val(158) met and fibromyalgia. Clinical and experimental rheumatology, 27(5 Suppl 56), S51-S56.

Cortes-Altamirano, J. L., Olmos-Hernandez, A., Jaime, H. B., Carrillo-Mora, P., Bandala, C., Reyes-Long, S., \& Alfaro-Rodríguez, A. (2018). Review: 5HT1, 5-HT2, 5-HT3 and 5-HT7 Receptors and their Role in the Modulation of Pain Response in the Central Nervous System. Current neuropharmacology, 16(2), 210-221. https://doi.org/10.2174/1570159X15666170911121027

Costa, B., Da Pozzo, E., \& Martini, C. (2012). Translocator protein as a promising target for novel anxiolytics. Current topics in medicinal chemistry, 12(4), 270-285. https://doi.org/10.2174/156802612799078720

da Silveira Alves, C. F., Caumo, W., Silvestri, J. M., Zortea, M., Dos Santos, V. S., Cardoso, D. F., Regner, A., de Souza, A. H., \& Simon, D. (2020). Pain catastrophizing is associated with the Val66Met polymorphism of the brain-derived neurotrophic factor in fibromyalgia. Advances in rheumatology (London, England), 60(1), 39. https://doi.org/10.1186/s42358-020-00141-9

Davies, P. A., Pistis, M., Hanna, M. C., Peters, J. A., Lambert, J. J., Hales, T. G., \& Kirkness, E. F. (1999). The 5-HT3B subunit is a major determinant of serotonin-receptor function. Nature, 397(6717), 359-363. https://doi.org/10.1038/16941

D'Agnelli, S., Arendt-Nielsen, L., Gerra, M. C., Zatorri, K., Boggiani, L., Baciarello, M., \& Bignami, E. (2019). Fibromyalgia: Genetics and epigenetics insights may provide the basis for the development of diagnostic biomarkers. Molecular pain, 15, 1744806918819944. https://doi.org/10.1177/1744806918819944

de Lima, L. O., Zicarelli, C., Matsumura, A. S., Moroti-Perugini, L. R., de Castro Teixeira, D., Fernandes, K., de Oliveira Perrucini, P. D., \& Poli-Frederico, R. C. (2019). Lower limb muscle strength and serotonin receptor gene polymorphism as factors associated in women with fibromyalgia. Advances in rheumatology (London, England), 59(1), 59. https://doi.org/10.1186/s42358-019-0101-9

DeRijk, R. H., Wüst, S., Meijer, O. C., Zennaro, M. C., Federenko, I. S., Hellhammer, D. H., Giacchetti, G., Vreugdenhil, E., Zitman, F. G., \& de Kloet, E. R. (2006). A common polymorphism in the mineralocorticoid receptor modulates stress responsiveness. The Journal of clinical endocrinology and metabolism, 91(12), 5083-5089. https://doi.org/10.1210/jc.2006-0915

Desmeules, J., Chabert, J., Rebsamen, M., Rapiti, E., Piguet, V., Besson, M., Dayer, P., \& Cedraschi, C. (2014). Central pain sensitization, COMT Val158Met polymorphism, and emotional factors in fibromyalgia. The journal of pain, 15(2), 129-135. https://doi.org/10.1016/j.jpain.2013.10.004 
Desmeules, J., Piguet, V., Besson, M., Chabert, J., Rapiti, E., Rebsamen, M., Rossier, M. F., Curtin, F., Dayer, P., \& Cedraschi, C. (2012). Psychological distress in fibromyalgia patients: a role for catechol-O-methyl-transferase Val158met polymorphism. Health psychology : official journal of the Division of Health Psychology, American Psychological Association, 31(2), 242-249. https://doi.org/10.1037/a0025223

Doan, L., Manders, T., \& Wang, J. (2015). Neuroplasticity underlying the comorbidity of pain and depression. Neural plasticity, 2015, 504691. https://doi.org/10.1155/2015/504691

Docampo, E., Escaramís, G., Gratacòs, M., Villatoro, S., Puig, A., Kogevinas, M., Collado, A., Carbonell, J., Rivera, J., Vidal, J., Alegre, J., Estivill, X., \& Rabionet, R. (2014). Genome-wide analysis of single nucleotide polymorphisms and copy number variants in fibromyalgia suggest a role for the central nervous system. Pain, 155(6), 1102-1109. https://doi.org/10.1016/j.pain.2014.02.016

Dolcino, M., Tinazzi, E., Puccetti, A., \& Lunardi, C. (2020). Gene Expression Profiling in Fibromyalgia Indicates an Autoimmune Origin of the Disease and Opens New Avenues for Targeted Therapy. Journal of clinical medicine, 9(6), 1814. https://doi.org/10.3390/jcm9061814

Ebstein, R. P., Novick, O., Umansky, R., Priel, B., Osher, Y., Blaine, D., Bennett, E. R., Nemanov, L., Katz, M., \& Belmaker, R. H. (1996). Dopamine D4 receptor (D4DR) exon III polymorphism associated with the human personality trait of Novelty Seeking. Nature genetics, 12(1), 78-80. https://doi.org/10.1038/ng0196-78

Egan, M. F., Kojima, M., Callicott, J. H., Goldberg, T. E., Kolachana, B. S., Bertolino, A., Zaitsev, E., Gold, B., Goldman, D., Dean, M., Lu, B., \& Weinberger, D. R. (2003). The BDNF val66met polymorphism affects activity-dependent secretion of BDNF and human memory and hippocampal function. Cell, 112(2), 257-269. https://doi.org/10.1016/s0092-8674(03)00035-7

Estacion, M., Harty, T. P., Choi, J. S., Tyrrell, L., Dib-Hajj, S. D., \& Waxman, S. G. (2009). A sodium channel gene SCN9A polymorphism that increases nociceptor excitability. Annals of neurology, 66(6), 862-866. https://doi.org/10.1002/ana.21895

Estévez-López, F., Aparicio, V. A., Ruiz, J. R., Martínez-González, L. J., Delgado-Fernández, M., \& Álvarez-Cubero, M. J. (2018a). The TT genotype of the rs6860 polymorphism of the charged multivesicular body protein 1A gene is associated with susceptibility to fibromyalgia in southern Spanish women. Rheumatology international, 38(3), 531-533. https://doi.org/10.1007/s00296-017-3896-x

Estévez-López, F., Camiletti-Moirón, D., Aparicio, V. A., Segura-Jiménez, V., Álvarez-Gallardo, I. C., Soriano-Maldonado, A., Borges-Cosic, M., AcostaManzano, P., Geenen, R., Delgado-Fernández, M., Martínez-González, L. J., Ruiz, J. R., \& Álvarez-Cubero, M. J. (2018b). Identification of candidate genes associated with fibromyalgia susceptibility in southern Spanish women: the al-Ándalus project. Journal of translational medicine, 16(1), 43. https://doi.org/10.1186/s12967-018-1416-8

Estévez-López, F., Guerrero-González, J. M., Salazar-Tortosa, D., Camiletti-Moirón, D., Gavilán-Carrera, B., Aparicio, V. A., Acosta-Manzano, P., ÁlvarezGallardo, I. C., Segura-Jiménez, V., Soriano-Maldonado, A., Geenen, R., Delgado-Fernández, M., Martínez-González, L. J., Ruiz, J. R., \& Álvarez-Cubero, M. J. (2021b). Interplay between genetics and lifestyle on pain susceptibility in women with fibromyalgia: The al-Ándalus project. Rheumatology (Oxford, England), keab911. Advance online publication. https://doi.org/10.1093/rheumatology/keab911

Estévez-López, F., Salazar-Tortosa, D. F., Camiletti-Moirón, D., Gavilán-Carrera, B., Aparicio, V. A., Acosta-Manzano, P., Segura-Jiménez, V., ÁlvarezGallardo, I. C., Carbonell-Baeza, A., Munguía-Izquierdo, D., Geenen, R., Lacerda, E., Delgado-Fernández, M., Martínez-González, L. J., Ruiz, J. R., \& Álvarez-Cubero, M. J. (2021a). Fatigue in Women with Fibromyalgia: A Gene-Physical Activity Interaction Study. Journal of clinical medicine, 10(9), 1902. https://doi.org/10.3390/jcm10091902

Fanton, S., Sandström, A., Tour, J., Kadetoff, D., Schalling, M., Jensen, K. B., Sitnikov, R., Ellerbrock, I., \& Kosek, E. (2021). The translocator protein gene is associated with endogenous pain modulation and the balance between glutamate and GABA in fibromyalgia and healthy subjects: a multimodal neuroimaging study. Pain, 10.1097/j.pain.0000000000002309. Advance online publication. https://doi.org/10.1097/j.pain.0000000000002309

Fernández-de-Las-Peñas, C., Ambite-Quesada, S., Gil-Crujera, A., Cigarán-Méndez, M., \& Peñacoba-Puente, C. (2012). Catechol-O-methyltransferase Val158Met polymorphism influences anxiety, depression, and disability, but not pressure pain sensitivity, in women with fibromyalgia syndrome. The journal of pain, 13(11), 1068-1074. https://doi.org/10.1016/j.jpain.2012.08.001

Ferrera, D., Gómez-Esquer, F., Peláez, I., Barjola, P., Fernandes-Magalhaes, R., Carpio, A., De Lahoz, M. E., Díaz-Gil, G., \& Mercado, F. (2020). Effects of COMT Genotypes on Working Memory Performance in Fibromyalgia Patients. Journal of clinical medicine, 9(8), 2479. https://doi.org/10.3390/jcm9082479

Ferrera, D., Mercado, F., Peláez, I., Martínez-Iñigo, D., Fernandes-Magalhaes, R., Barjola, P., Écija, C., Díaz-Gil, G., \& Gómez-Esquer, F. (2021). Fear of pain moderates the relationship between self-reported fatigue and methionine allele of catechol-O-methyltransferase gene in patients with fibromyalgia. PloS one, 16(4), e0250547. https://doi.org/10.1371/journal.pone.0250547

Finan, P. H., Zautra, A. J., Davis, M. C., Lemery-Chalfant, K., Covault, J., \& Tennen, H. (2010). Genetic influences on the dynamics of pain and affect in fibromyalgia. Health psychology : official journal of the Division of Health Psychology, American Psychological Association, 29(2), 134-142. https://doi.org/10.1037/a0018647

Finan, P. H., Zautra, A. J., Davis, M. C., Lemery-Chalfant, K., Covault, J., \& Tennen, H. (2011). COMT moderates the relation of daily maladaptive coping and pain in fibromyalgia. Pain, 152(2), 300-307. https://doi.org/10.1016/j.pain.2010.10.024

Fitzcharles, M. A., Ste-Marie, P. A., Goldenberg, D. L., Pereira, J. X., Abbey, S., Choinière, M., Ko, G., Moulin, D. E., Panopalis, P., Proulx, J., Shir, Y., \& National Fibromyalgia Guideline Advisory Panel (2013). 2012 Canadian Guidelines for the diagnosis and management of fibromyalgia syndrome: executive summary. Pain research \& management, 18(3), 119-126. https://doi.org/10.1155/2013/918216

Fitzcharles, M. A., Perrot, S., \& Häuser, W. (2018). Comorbid fibromyalgia: A qualitative review of prevalence and importance. European journal of pain (London, England), 22(9), 1565-1576. https://doi.org/10.1002/ejp.1252

Flatters S. J. (2015). The contribution of mitochondria to sensory processing and pain. Progress in molecular biology and translational science, 131, 119-146. https://doi.org/10.1016/bs.pmbts.2014.12.004 
Gaughan, D. J., Barbaux, S., Kluijtmans, L. A., \& Whitehead, A. S. (2000). The human and mouse methylenetetrahydrofolate reductase (MTHFR) genes: genomic organization, mRNA structure and linkage to the CLCN6 gene. Gene, 257(2), 279-289. https://doi.org/10.1016/s0378-1119(00)00392-9

Gelernter, J., Pakstis, A. J., \& Kidd, K. K. (1995). Linkage mapping of serotonin transporter protein gene SLC6A4 on chromosome 17. Human genetics, 95(6), 677-680. https://doi.org/10.1007/BF00209486

Gerra, M. C., Carnevali, D., Ossola, P., González-Villar, A., Pedersen, I. S., Triñanes, Y., Donnini, C., Manfredini, M., Arendt-Nielsen, L., \& Carrillo-de-laPeña, M. T. (2021). DNA Methylation Changes in Fibromyalgia Suggest the Role of the Immune-Inflammatory Response and Central Sensitization. Journal of clinical medicine, 10(21), 4992. https://doi.org/10.3390/jcm10214992

Gerra, M. C., Carnevali, D., Pedersen, I. S., Donnini, C., Manfredini, M., González-Villar, A., Triñanes, Y., Pidal-Miranda, M., Arendt-Nielsen, L., \& Carrillo-de-la-Peña, M. T. (2020). DNA methylation changes in genes involved in inflammation and depression in fibromyalgia: a pilot study. Scandinavian journal of pain, 21(2), 372-383. https://doi.org/10.1515/sjpain-2020-0124

Gogos, J. A., Morgan, M., Luine, V., Santha, M., Ogawa, S., Pfaff, D., \& Karayiorgou, M. (1998). Catechol-O-methyltransferase-deficient mice exhibit sexually dimorphic changes in catecholamine levels and behavior. Proceedings of the National Academy of Sciences of the United States of America, 95(17), 9991-9996. https://doi.org/10.1073/pnas.95.17.9991

Graeff F. G. (1997). Serotonergic systems. The Psychiatric clinics of North America, 20(4), 723-739. https://doi.org/10.1016/s0193-953x(05)70342-7

Gursoy S. (2002). Absence of association of the serotonin transporter gene polymorphism with the mentally healthy subset of fibromyalgia patients. Clinical rheumatology, 21(3), 194-197. https://doi.org/10.1007/s10067-002-8284-5

Gürsoy, S., Erdal, E., Herken, H., Madenci, E., \& Alaşehirli, B. (2001). Association of T102C polymorphism of the 5-HT2A receptor gene with psychiatric status in fibromyalgia syndrome. Rheumatology international, 21(2), 58-61. https://doi.org/10.1007/s002960100130

Gürsoy, S., Erdal, E., Herken, H., Madenci, E., Alaşehirli, B., \& Erdal, N. (2003). Significance of catechol-O-methyltransferase gene polymorphism in fibromyalgia syndrome. Rheumatology international, 23(3), 104-107. https://doi.org/10.1007/s00296-002-0260-5

Gürsoy, S., Erdal, E., Sezgin, M., Barlas, I. O., Aydeniz, A., Alaşehirli, B., \& Sahin, G. (2008). Which genotype of MAO gene that the patients have are likely to be most susceptible to the symptoms of fibromyalgia?. Rheumatology international, 28(4), 307-311. https://doi.org/10.1007/s00296-007-0454-y

Hannon, J., \& Hoyer, D. (2008). Molecular biology of 5-HT receptors. Behavioural brain research, 195(1), 198-213. https://doi.org/10.1016/j.bbr.2008.03.020

Hanson, I. M., Seawright, A., \& van Heyningen, V. (1992). The human BDNF gene maps between FSHB and HVBS1 at the boundary of 11p13-p14. Genomics, 13(4), 1331-1333. https://doi.org/10.1016/0888-7543(92)90060-6

Hariri, A. R., Mattay, V. S., Tessitore, A., Kolachana, B., Fera, F., Goldman, D., Egan, M. F., \& Weinberger, D. R. (2002). Serotonin transporter genetic variation and the response of the human amygdala. Science (New York, N.Y.), 297(5580), 400-403. https://doi.org/10.1126/science.1071829

Harris, R. E., \& Clauw, D. J. (2006). How do we know that the pain in fibromyalgia is "real"?. Current pain and headache reports, 10(6), 403-407. https://doi.org/10.1007/s11916-006-0069-0

Harris, R. E., Clauw, D. J., Scott, D. J., McLean, S. A., Gracely, R. H., \& Zubieta, J. K. (2007). Decreased central mu-opioid receptor availability in fibromyalgia. The Journal of neuroscience: the official journal of the Society for Neuroscience, 27(37), 10000-10006. https://doi.org/10.1523/JNEUROSCI.2849-07.2007

Hatami, M., Sobhan, M. R., Dastgheib, S. A., Jarahzadeh, M. H., Jafari, M., Yadegari, A., Sadeghizadeh-Yazdi, J., \& Neamatzadeh, H. (2020). Association of catechol-O-methyltranferase 472G>A (Val158Met) polymorphism with susceptibility to fibromyalgia syndrome. Journal of orthopaedics, 20, 257-260. https://doi.org/10.1016/j.jor.2020.01.013

Heddini, U., Bohm-Starke, N., Grönbladh, A., Nyberg, F., Nilsson, K. W., \& Johannesson, U. (2014). Serotonin receptor gene (5HT-2A) polymorphism is associated with provoked vestibulodynia and comorbid symptoms of pain. The journal of sexual medicine, 11(12), 3064-3071. https://doi.org/10.1111/jsm.12685

Heils, A., Teufel, A., Petri, S., Stöber, G., Riederer, P., Bengel, D., \& Lesch, K. P. (1996). Allelic variation of human serotonin transporter gene expression. Journal of neurochemistry, 66(6), 2621-2624. https://doi.org/10.1046/j.1471-4159.1996.66062621.x

Hocking, L. J., Smith, B. H., Jones, G. T., Reid, D. M., Strachan, D. P., \& Macfarlane, G. J. (2010). Genetic variation in the beta2-adrenergic receptor but not catecholamine-O-methyltransferase predisposes to chronic pain: results from the 1958 British Birth Cohort Study. Pain, 149(1), 143-151. https://doi.org/10.1016/j.pain.2010.01.023

Hoehe, M. R., Berrettini, W. H., Schwinn, D. A., \& Hsieh, W. T. (1992). A two-allele PstI RFLP for the alpha-1C adrenergic receptor gene (ADRA1C). Human molecular genetics, 1(5), 349. https://doi.org/10.1093/hmg/1.5.349-a

Inanir, A., Karakus, N., Ates, O., Sezer, S., Bozkurt, N., Inanir, S., \& Yigit, S. (2014). Clinical symptoms in fibromyalgia are associated to catechol-Omethyltransferase (COMT) gene Val158Met polymorphism. Xenobiotica; the fate of foreign compounds in biological systems, 44(10), 952-956. https://doi.org/10.3109/00498254.2014.913083

Inanir, A., Yigit, S., Tekcan, A., Pinarli, F. A., Inanir, S., \& Karakus, N. (2015). Angiotensin converting enzyme and methylenetetrahydrofolate reductase gene variations in fibromyalgia syndrome. Gene, 564(2), 188-192. https://doi.org/10.1016/j.gene.2015.03.051

Inoue, A., Yanagisawa, M., Takuwa, Y., Mitsui, Y., Kobayashi, M., \& Masaki, T. (1989). The human preproendothelin-1 gene. Complete nucleotide sequence and regulation of expression. The Journal of biological chemistry, 264(25), 14954-14959. 
Josep García-Fructuoso, F., Ignacio Lao-Villadóniga, J., Beyer, K., \& Santos, C. (2006). Relación entre genotipos del gen catecol O-metiltransferasa y la gravedad de la fibromialgia [Relationship between COMT gene genotypes and severity of fibromyalgia]. Reumatologia clinica, 2(4), 168-172. https://doi.org/10.1016/S1699-258X(06)73042-X

Karakus, N., Yigit, S., Inanir, A., Inanir, S., Toprak, H., \& Okan, S. (2012). Association between sequence variations of the Mediterranean fever gene and fibromyalgia syndrome in a cohort of Turkish patients. Clinica chimica acta; international journal of clinical chemistry, 414, 36-40. https://doi.org/10.1016/j.cca.2012.07.019

Karoly, P., \& Ruehlman, L. S. (2006). Psychological "resilience" and its correlates in chronic pain: findings from a national community sample. Pain, 123(12), 90-97. https://doi.org/10.1016/j.pain.2006.02.014

Kato, K., Sullivan, P. F., Evengård, B., \& Pedersen, N. L. (2009). A population-based twin study of functional somatic syndromes. Psychological medicine, 39(3), 497-505. https://doi.org/10.1017/S0033291708003784

Khalil, R., Al-Awaida, W. J., Al-Ameer, H. J., Jarrar, Y., Imraish, A., Al Bawareed, O., Qawadri, R., Al Madhoon, F., \& Obeidat, L. (2020). Investigation of ACE rs4646994, MTHFR rs1801133 and VDR rs2228570 Genotypes in Jordanian Patients with Fibromyalgia Syndrome. Endocrine, metabolic \& immune disorders drug targets, 10.2174/1871530321666201223104622. Advance online publication. https://doi.org/10.2174/1871530321666201223104622

Kilpatrick, L. A., Labus, J. S., Coveleskie, K., Hammer, C., Rappold, G., Tillisch, K., Bueller, J. A., Suyenobu, B., Jarcho, J. M., McRoberts, J. A., Niesler, B., \& Mayer, E. A. (2011). The HTR3A polymorphism c. $-42 \mathrm{C}>\mathrm{T}$ is associated with amygdala responsiveness in patients with irritable bowel syndrome. Gastroenterology, 140(7), 1943-1951. https://doi.org/10.1053/j.gastro.2011.03.011

Kim, S. K., Kim, S. H., Nah, S. S., Lee, J. H., Hong, S. J., Kim, H. S., Lee, H. S., Kim, H. A., Joung, C. I., Bae, J., Choe, J. Y., \& Lee, S. S. (2013). Association of guanosine triphosphate cyclohydrolase 1 gene polymorphisms with fibromyalgia syndrome in a Korean population. The Journal of rheumatology, 40(3), 316-322. https://doi.org/10.3899/jrheum.120929

Klengel, T., Pape, J., Binder, E. B., \& Mehta, D. (2014). The role of DNA methylation in stress-related psychiatric disorders. Neuropharmacology, 80, 115132. https://doi.org/10.1016/j.neuropharm.2014.01.013

Kling, A., Seddighzadeh, M., Arlestig, L., Alfredsson, L., Rantapää-Dahlqvist, S., \& Padyukov, L. (2008). Genetic variations in the serotonin 5-HT2A receptor gene (HTR2A) are associated with rheumatoid arthritis. Annals of the rheumatic diseases, 67(8), 1111-1115. https://doi.org/10.1136/ard.2007.074948

Kosek, E., Martinsen, S., Gerdle, B., Mannerkorpi, K., Löfgren, M., Bileviciute-Ljungar, I., Fransson, P., Schalling, M., Ingvar, M., Ernberg, M., \& Jensen, K. B. (2016). The translocator protein gene is associated with symptom severity and cerebral pain processing in fibromyalgia. Brain, behavior, and immunity, 58, 218-227. https://doi.org/10.1016/j.bbi.2016.07.150

Krzywkowski, K., Davies, P. A., Feinberg-Zadek, P. L., Bräuner-Osborne, H., \& Jensen, A. A. (2008). High-frequency HTR3B variant associated with major depression dramatically augments the signaling of the human 5-HT3AB receptor. Proceedings of the National Academy of Sciences of the United States of America, 105(2), 722-727. https://doi.org/10.1073/pnas.0708454105

Kuryliszyn-Moskal, A., Klimiuk, P. A., Sierakowski, S., \& Ciolkiewicz, M. (2006). A study on vascular endothelial growth factor and endothelin-1 in patients with extra-articular involvement of rheumatoid arthritis. Clinical rheumatology, 25(3), 314-319. https://doi.org/10.1007/s10067-005-0007-2

Lachaine, J., Beauchemin, C., \& Landry, P. A. (2010). Clinical and economic characteristics of patients with fibromyalgia syndrome. The Clinical journal of pain, 26(4), 284-290. https://doi.org/10.1097/AJP.0b013e3181cf599f

Lang, U. E., Hellweg, R., Kalus, P., Bajbouj, M., Lenzen, K. P., Sander, T., Kunz, D., \& Gallinat, J. (2005). Association of a functional BDNF polymorphism and anxiety-related personality traits. Psychopharmacology, 180(1), 95-99. https://doi.org/10.1007/s00213-004-2137-7

Ledermann, K., Hasler, G., Jenewein, J., Sprott, H., Schnyder, U., \& Martin-Soelch, C. (2020). 5'UTR polymorphism in the serotonergic receptor HTR3A gene is differently associated with striatal Dopamine D2/D3 receptor availability in the right putamen in Fibromyalgia patients and healthy controlsPreliminary evidence. Synapse (New York, N.Y.), 74(5), e22147. https://doi.org/10.1002/syn.22147

Lee, C., Liptan, G., Kantorovich, S., Sharma, M., \& Brenton, A. (2018). Association of Catechol-O-methyltransferase single nucleotide polymorphisms, ethnicity, and sex in a large cohort of fibromyalgia patients. BMC rheumatology, 2, 38. https://doi.org/10.1186/s41927-018-0045-4

Lee, Y. H., Choi, S. J., Ji, J. D., \& Song, G. G. (2012). Candidate gene studies of fibromyalgia: a systematic review and meta-analysis. Rheumatology international, 32(2), 417-426. https://doi.org/10.1007/s00296-010-1678-9

Lesch, K. P., Bengel, D., Heils, A., Sabol, S. Z., Greenberg, B. D., Petri, S., Benjamin, J., Müller, C. R., Hamer, D. H., \& Murphy, D. L. (1996). Association of anxiety-related traits with a polymorphism in the serotonin transporter gene regulatory region. Science (New York, N.Y.), 274(5292), 1527-1531. https://doi.org/10.1126/science.274.5292.1527

Levine, J. D., \& Alessandri-Haber, N. (2007). TRP channels: targets for the relief of pain. Biochimica et biophysica acta, 1772(8), 989-1003. https://doi.org/10.1016/j.bbadis.2007.01.008

Lloyd, D. M., Wittkopf, P. G., Arendsen, L. J., \& Jones, A. (2020). Is Transcranial Direct Current Stimulation (tDCS) Effective for the Treatment of Pain in Fibromyalgia? A Systematic Review and Meta-Analysis. The journal of pain, 21(11-12), 1085-1100. https://doi.org/10.1016/j.jpain.2020.01.003

Low, L. A., \& Schweinhardt, P. (2012). Early life adversity as a risk factor for fibromyalgia in later life. Pain research and treatment, $2012,140832$. https://doi.org/10.1155/2012/140832

Lusis, A. J., Heinzmann, C., Sparkes, R. S., Scott, J., Knott, T. J., Geller, R., Sparkes, M. C., \& Mohandas, T. (1986). Regional mapping of human chromosome 19: organization of genes for plasma lipid transport (APOC1, -C2, and -E and LDLR) and the genes C3, PEPD, and GPI. Proceedings of the National Academy of Sciences of the United States of America, 83(11), 3929-3933. https://doi.org/10.1073/pnas.83.11.3929 
Macedo, J. A., Hesse, J., Turner, J. D., Meyer, J., Hellhammer, D. H., \& Muller, C. P. (2008). Glucocorticoid sensitivity in fibromyalgia patients: decreased expression of corticosteroid receptors and glucocorticoid-induced leucine zipper. Psychoneuroendocrinology, 33(6), 799-809. https://doi.org/10.1016/j.psyneuen.2008.03.012

Macfarlane, G. J., Kronisch, C., Dean, L. E., Atzeni, F., Häuser, W., Fluß, E., Choy, E., Kosek, E., Amris, K., Branco, J., Dincer, F., Leino-Arjas, P., Longley, K., McCarthy, G. M., Makri, S., Perrot, S., Sarzi-Puttini, P., Taylor, A., \& Jones, G. T. (2017). EULAR revised recommendations for the management of fibromyalgia. Annals of the rheumatic diseases, 76(2), 318-328. https://doi.org/10.1136/annrheumdis-2016-209724

Maricq, A. V., Peterson, A. S., Brake, A. J., Myers, R. M., \& Julius, D. (1991). Primary structure and functional expression of the 5HT3 receptor, a serotoningated ion channel. Science (New York, N.Y.), 254(5030), 432-437. https://doi.org/10.1126/science.1718042

Markkula, R., Järvinen, P., Leino-Arjas, P., Koskenvuo, M., Kalso, E., \& Kaprio, J. (2009). Clustering of symptoms associated with fibromyalgia in a Finnish Twin Cohort. European journal of pain (London, England), 13(7), 744-750. https://doi.org/10.1016/j.ejpain.2008.09.007

Marques, A. P., Santos, A. M. B., Assumpção, A., Matsutani, L. A., Lage, L. V. \& Pereira, C. A. B. (2006). Validation of the brazilian version of the fibromyalgia impact questionnaire (FIQ). Revista brasileira de reumatologia, 46(1), 24-31. https://doi.org/10.1590/S0482-50042006000100006

Marques, A. P., Santo, A., Berssaneti, A. A., Matsutani, L. A., \& Yuan, S. (2017). Prevalence of fibromyalgia: literature review update. Revista brasileira de reumatologia, 57(4), 356-363. https://doi.org/10.1016/j.rbre.2017.01.005

Martínez-Jauand, M., Sitges, C., Rodríguez, V., Picornell, A., Ramon, M., Buskila, D., \& Montoya, P. (2013). Pain sensitivity in fibromyalgia is associated with catechol-O-methyltransferase (COMT) gene. European journal of pain (London, England), 17(1), 16-27. https://doi.org/10.1002/j.15322149.2012.00153.x

Masters, S. L., Lagou, V., Jéru, I., Baker, P. J., Van Eyck, L., Parry, D. A., Lawless, D., De Nardo, D., Garcia-Perez, J. E., Dagley, L. F., Holley, C. L., Dooley, J., Moghaddas, F., Pasciuto, E., Jeandel, P. Y., Sciot, R., Lyras, D., Webb, A. I., Nicholson, S. E., De Somer, L., ... Liston, A. (2016). Familial autoinflammation with neutrophilic dermatosis reveals a regulatory mechanism of pyrin activation. Science translational medicine, 8(332), 332ra45. https://doi.org/10.1126/scitranslmed.aaf1471

Matsuda, J. B., Barbosa, F. R., Morel, L. J., França, S., Zingaretti, S. M., da Silva, L. M., Pereira, A. M., Marins, M., \& Fachin, A. L. (2010). Serotonin receptor (5-HT 2A) and catechol-O-methyltransferase (COMT) gene polymorphisms: triggers of fibromyalgia?. Revista brasileira de reumatologia, 50(2), $141-149$.

McAllister, S. J., Vincent, A., Hassett, A. L., Whipple, M. O., Oh, T. H., Benzo, R. P., \& Toussaint, L. L. (2015). Psychological Resilience, Affective Mechanisms and Symptom Burden in a Tertiary-care Sample of Patients with Fibromyalgia. Stress and health : journal of the International Society for the Investigation of Stress, 31(4), 299-305. https://doi.org/10.1002/smi.2555

Meeker, T. J., Jupudi, R., Lenz, F. A., \& Greenspan, J. D. (2020). New Developments in Non-invasive Brain Stimulation in Chronic Pain. Current physical medicine and rehabilitation reports, 8(3), 280-292. https://doi.org/10.1007/s40141-020-00260-w

Menzies, V., Lyon, D. E., Archer, K. J., Zhou, Q., Brumelle, J., Jones, K. H., Gao, G., York, T. P., \& Jackson-Cook, C. (2013). Epigenetic alterations and an increased frequency of micronuclei in women with fibromyalgia. Nursing research and practice, 2013, 795784. https://doi.org/10.1155/2013/795784

Michiels, J. J., te Morsche, R. H., Jansen, J. B., \& Drenth, J. P. (2005). Autosomal dominant erythermalgia associated with a novel mutation in the voltagegated sodium channel alpha subunit Nav1.7. Archives of neurology, 62(10), 1587-1590. https://doi.org/10.1001/archneur.62.10.1587

Miyake, A., Mochizuki, S., Takemoto, Y., \& Akuzawa, S. (1995). Molecular cloning of human 5-hydroxytryptamine3 receptor: heterogeneity in distribution and function among species. Molecular pharmacology, 48(3), 407-416.

Mogil J. S. (2012). Pain genetics: past, present and future. Trends in genetics : TIG, 28(6), 258-266. https://doi.org/10.1016/j.tig.2012.02.004

Moriam, S., \& Sobhani, M. E. (2013). Epigenetic effect of chronic stress on dopamine signaling and depression. Genetics \& epigenetics, 5, 11-16. https://doi.org/10.4137/GEG.S11016

Mortensen, E. L., \& Høgh, P. (2001). A gender difference in the association between APOE genotype and age-related cognitive decline. Neurology, 57(1), 8995. https://doi.org/10.1212/wnl.57.1.89

Nackley, A. G., Tan, K. S., Fecho, K., Flood, P., Diatchenko, L., \& Maixner, W. (2007). Catechol-O-methyltransferase inhibition increases pain sensitivity through activation of both beta2- and beta3-adrenergic receptors. Pain, 128(3), 199-208. https://doi.org/10.1016/j.pain.2006.09.022

Nah, S. S., Lee, H., Hong, Y., Im, J., Won, H., Chang, S. H., Kim, H. K., Kwon, J. T., \& Kim, H. J. (2017). Association between endothelin-1 and fibromyalgia syndrome. Molecular medicine reports, 16(5), 6234-6239. https://doi.org/10.3892/mmr.2017.7395

Najera, K., Fagan, B. M., \& Thompson, P. M. (2019). SNAP-25 in Major Psychiatric Disorders: A Review. Neuroscience, 420, 79-85. https://doi.org/10.1016/j.neuroscience.2019.02.008

Nicholl, B. I., Holliday, K. L., Macfarlane, G. J., Thomson, W., Davies, K. A., O'Neill, T. W., Bartfai, G., Boonen, S., Casanueva, F., Finn, J. D., Forti, G., Giwercman, A., Huhtaniemi, I. T., Kula, K., Punab, M., Silman, A. J., Vanderschueren, D., Wu, F. C., McBeth, J., \& European Male Ageing Study Group (2010). No evidence for a role of the catechol-O-methyltransferase pain sensitivity haplotypes in chronic widespread pain. Annals of the rheumatic diseases, 69(11), 2009-2012. https://doi.org/10.1136/ard.2009.126086

Nugraha, B., Anwar, S. L., Gutenbrunner, C., \& Korallus, C. (2020). Polymorphisms of brain-derived neurotrophic factor genes are associated with anxiety and body mass index in fibromyalgia syndrome patients. BMC research notes, 13(1), 402. https://doi.org/10.1186/s13104-020-05226-8

Offenbaecher, M., Bondy, B., de Jonge, S., Glatzeder, K., Krüger, M., Schoeps, P., \& Ackenheil, M. (1999). Possible association of fibromyalgia with a polymorphism in the serotonin transporter gene regulatory region. Arthritis and rheumatism, 42(11), 2482-2488. https://doi.org/10.1002/15290131(199911)42:11<2482::AID-ANR27>3.0.CO;2-B 
Pache, M., Schwarz, H. A., Kaiser, H. J., Wüest, P., Klöti, M., Dubler, B., \& Flammer, J. (2002). Elevated plasma endothelin-1 levels and vascular dysregulation in patients with rheumatoid arthritis. Medical science monitor : international medical journal of experimental and clinical research, 8(9), CR616CR619.

Pages, J. C., Drieu, C., Blanché, H., Beckmann, J., \& Cann, H. M. (1993). A short tandem repeat polymorphism at the endothelin 1 (EDN1) locus. Human molecular genetics, 2(1), 90. https://doi.org/10.1093/hmg/2.1.90

Paiva, E. S., Heymann, R. E., Rezende, M. C., Helfenstein, M., Jr, Martinez, J. E., Provenza, J. R., Ranzolin, A., de Assis, M. R., Pasqualin, V. D., \& Bennett, R. M. (2013). A Brazilian Portuguese version of the Revised Fibromyalgia Impact Questionnaire (FIQR): a validation study. Clinical rheumatology, 32(8), 1199-1206. https://doi.org/10.1007/s10067-013-2259-6

Park, D. J., Kang, J. H., Yim, Y. R., Kim, J. E., Lee, J. W., Lee, K. E., Wen, L., Kim, T. J., Park, Y. W., \& Lee, S. S. (2015). Exploring Genetic Susceptibility to Fibromyalgia. Chonnam medical journal, 51(2), 58-65. https://doi.org/10.4068/cmj.2015.51.2.58

Park, D. J., Kim, S. H., Nah, S. S., Lee, J. H., Kim, S. K., Lee, Y. A., Hong, S. J., Kim, H. S., Lee, H. S., Kim, H. A., Joung, C. I., Kim, S. H., \& Lee, S. S. (2016a). Association between catechol-O-methyl transferase gene polymorphisms and fibromyalgia in a Korean population: A case-control study. European journal of pain (London, England), 20(7), 1131-1139. https://doi.org/10.1002/ejp.837

Park, D. J., Kim, S. H., Nah, S. S., Lee, J. H., Kim, S. K., Lee, Y. A., Hong, S. J., Kim, H. S., Lee, H. S., Kim, H. A., Joung, C. I., Kim, S. H., \& Lee, S. S. (2016b). Polymorphisms of the TRPV2 and TRPV3 genes associated with fibromyalgia in a Korean population. Rheumatology (Oxford, England), 55(8), 1518-1527. https://doi.org/10.1093/rheumatology/kew180

Park, D. J., Kim, S. H., Nah, S. S., Lee, J. H., Kim, S. K., Lee, Y. A., Hong, S. J., Kim, H. S., Lee, H. S., Kim, H. A., Joung, C. I., Kim, S. H., \& Lee, S. S. (2018). Association between brain-derived neurotrophic factor gene polymorphisms and fibromyalgia in a Korean population: a multicenter study. Arthritis research \& therapy, 20(1), 220. https://doi.org/10.1186/s13075-018-1726-5

Park, H., \& Poo, M. M. (2013). Neurotrophin regulation of neural circuit development and function. Nature reviews. Neuroscience, 14(1), 7-23. https://doi.org/10.1038/nrn3379

Parsons, M. J., D'Souza, U. M., Arranz, M. J., Kerwin, R. W., \& Makoff, A. J. (2004). The -1438A/G polymorphism in the 5-hydroxytryptamine type 2A receptor gene affects promoter activity. Biological psychiatry, 56(6), 406-410. https://doi.org/10.1016/j.biopsych.2004.06.020

Pearson-Fuhrhop, K. M., Dunn, E. C., Mortero, S., Devan, W. J., Falcone, G. J., Lee, P., Holmes, A. J., Hollinshead, M. O., Roffman, J. L., Smoller, J. W., Rosand, J., \& Cramer, S. C. (2014). Dopamine genetic risk score predicts depressive symptoms in healthy adults and adults with depression. PloS one, 9(5), e93772. https://doi.org/10.1371/journal.pone.0093772

Pereira, M.G. (2012). Artigos científicos: como redigir, publicar e avaliar. Rio de Janeiro: Guanabara Koogan. p.47-48.

Pertovaara A. (2006). Noradrenergic pain modulation. Progress in neurobiology, 80(2), 53-83. https://doi.org/10.1016/j.pneurobio.2006.08.001

Polli, A., Ghosh, M., Bakusic, J., Ickmans, K., Monteyne, D., Velkeniers, B., Bekaert, B., Godderis, L., \& Nijs, J. (2020). DNA Methylation and BrainDerived Neurotrophic Factor Expression Account for Symptoms and Widespread Hyperalgesia in Patients With Chronic Fatigue Syndrome and Comorbid Fibromyalgia. Arthritis \& rheumatology (Hoboken, N.J.), 72(11), 1936-1944. https://doi.org/10.1002/art.41405

Potvin, S., Larouche, A., Normand, E., de Souza, J. B., Gaumond, I., Grignon, S., \& Marchand, S. (2009). DRD3 Ser9Gly polymorphism is related to thermal pain perception and modulation in chronic widespread pain patients and healthy controls. The journal of pain, 10(9), 969-975. https://doi.org/10.1016/j.jpain.2009.03.013

Pozzi, D., Corradini, I., \& Matteoli, M. (2019). The Control of Neuronal Calcium Homeostasis by SNAP-25 and its Impact on Neurotransmitter Release. Neuroscience, 420, 72-78. https://doi.org/10.1016/j.neuroscience.2018.11.009

Queiroz L. P. (2013). Worldwide epidemiology of fibromyalgia. Current pain and headache reports, 17(8), 356. https://doi.org/10.1007/s11916-013-0356-5

Ramamoorthy, S., Bauman, A. L., Moore, K. R., Han, H., Yang-Feng, T., Chang, A. S., Ganapathy, V., \& Blakely, R. D. (1993). Antidepressant- and cocainesensitive human serotonin transporter: molecular cloning, expression, and chromosomal localization. Proceedings of the National Academy of Sciences of the United States of America, 90(6), 2542-2546. https://doi.org/10.1073/pnas.90.6.2542

Reeser, J. C., Payne, E., Kitchner, T., \& McCarty, C. A. (2011). Apolipoprotein e4 genotype increases the risk of being diagnosed with posttraumatic fibromyalgia. PM \& R : the journal of injury, function, and rehabilitation, 3(3), 193-197. https://doi.org/10.1016/j.pmrj.2010.12.009

Reichborn-Kjennerud, T., Stoltenberg, C., Tambs, K., Roysamb, E., Kringlen, E., Torgersen, S., \& Harris, J. R. (2002). Back-neck pain and symptoms of anxiety and depression: a population-based twin study. Psychological medicine, 32(6), 1009-1020. https://doi.org/10.1017/s0033291702005950

Reimann, F., Cox, J. J., Belfer, I., Diatchenko, L., Zaykin, D. V., McHale, D. P., Drenth, J. P., Dai, F., Wheeler, J., Sanders, F., Wood, L., Wu, T. X., Karppinen, J., Nikolajsen, L., Männikkö, M., Max, M. B., Kiselycznyk, C., Poddar, M., Te Morsche, R. H., Smith, S., ... Woods, C. G. (2010). Pain perception is altered by a nucleotide polymorphism in SCN9A. Proceedings of the National Academy of Sciences of the United States of America, 107(11), 5148-5153. https://doi.org/10.1073/pnas.0913181107

Russell, I. J., Michalek, J. E., Vipraio, G. A., Fletcher, E. M., Javors, M. A., \& Bowden, C. A. (1992a). Platelet 3H-imipramine uptake receptor density and serum serotonin levels in patients with fibromyalgia/fibrositis syndrome. The Journal of rheumatology, 19(1), 104-109.

Russell, I. J., Vaeroy, H., Javors, M., \& Nyberg, F. (1992b). Cerebrospinal fluid biogenic amine metabolites in fibromyalgia/fibrositis syndrome and rheumatoid arthritis. Arthritis and rheumatism, 35(5), 550-556. https://doi.org/10.1002/art.1780350509

Sarzi-Puttini, P., Giorgi, V., Marotto, D., \& Atzeni, F. (2020). Fibromyalgia: an update on clinical characteristics, aetiopathogenesis and treatment. Nature reviews. Rheumatology, 16(11), 645-660. https://doi.org/10.1038/s41584-020-00506-w 
Schmechel, D. E., \& Edwards, C. L. (2012). Fibromyalgia, mood disorders, and intense creative energy: A1AT polymorphisms are not always silent. Neurotoxicology, 33(6), 1454-1472. https://doi.org/10.1016/j.neuro.2012.03.001

Schwinn, D. A., Lomasney, J. W., Lorenz, W., Szklut, P. J., Fremeau, R. T., Jr, Yang-Feng, T. L., Caron, M. G., Lefkowitz, R. J., \& Cotecchia, S. (1990). Molecular cloning and expression of the cDNA for a novel alpha 1-adrenergic receptor subtype. The Journal of biological chemistry, 265(14), 8183-8189.

Scott, I. C., Halila, R., Jenkins, J. M., Mehan, S., Apostolou, S., Winqvist, R., Callen, D. F., Prockop, D. J., Peltonen, L., \& Kadler, K. E. (1996). Molecular cloning, expression and chromosomal localization of a human gene encoding a $33 \mathrm{kDa}$ putative metallopeptidase (PRSM1). Gene, 174(1), 135-143. https://doi.org/10.1016/0378-1119(96)00510-0

Scudds, R. A., Li EK-M., Scudds R. J. (2006). The prevalence of fibromyalgia syndrome in Chinese people in Hong Kong. J Musculoskelet Pain, 14:3-11. https://doi.org/10.1300/J094v14n02_02

Senna, E. R., De Barros, A. L., Silva, E. O., Costa, I. F., Pereira, L. V., Ciconelli, R. M., \& Ferraz, M. B. (2004). Prevalence of rheumatic diseases in Brazil: a study using the COPCORD approach. The Journal of rheumatology, 31(3), 594-597.

Shen, S., Battersby, S., Weaver, M., Clark, E., Stephens, K., \& Harmar, A. J. (2000). Refined mapping of the human serotonin transporter (SLC6A4) gene within 17q11 adjacent to the CPD and NF1 genes. European journal of human genetics : EJHG, 8(1), 75-78. https://doi.org/10.1038/sj.ejhg.5200400

Shimizu, E., Hashimoto, K., Okamura, N., Koike, K., Komatsu, N., Kumakiri, C., Nakazato, M., Watanabe, H., Shinoda, N., Okada, S., \& Iyo, M. (2003). Alterations of serum levels of brain-derived neurotrophic factor (BDNF) in depressed patients with or without antidepressants. Biological psychiatry, 54(1), 70-75. https://doi.org/10.1016/s0006-3223(03)00181-1

Sluka, K. A., \& Clauw, D. J. (2016). Neurobiology of fibromyalgia and chronic widespread pain. Neuroscience, 338, 114-129. https://doi.org/10.1016/j.neuroscience.2016.06.006

Small, K. M., McGraw, D. W., \& Liggett, S. B. (2003). Pharmacology and physiology of human adrenergic receptor polymorphisms. Annual review of pharmacology and toxicology, 43, 381-411. https://doi.org/10.1146/annurev.pharmtox.43.100901.135823

Smith, S. B., Maixner, D. W., Fillingim, R. B., Slade, G., Gracely, R. H., Ambrose, K., Zaykin, D. V., Hyde, C., John, S., Tan, K., Maixner, W., \& Diatchenko, L. (2012). Large candidate gene association study reveals genetic risk factors and therapeutic targets for fibromyalgia. Arthritis and rheumatism, 64(2), 584-593. https://doi.org/10.1002/art.33338

Spurlock, G., Heils, A., Holmans, P., Williams, J., D'Souza, U. M., Cardno, A., Murphy, K. C., Jones, L., Buckland, P. R., McGuffin, P., Lesch, K. P., \& Owen, M. J. (1998). A family based association study of T102C polymorphism in 5HT2A and schizophrenia plus identification of new polymorphisms in the promoter. Molecular psychiatry, 3(1), 42-49. https://doi.org/10.1038/sj.mp.4000342

Stein, M. B., Campbell-Sills, L., \& Gelernter, J. (2009). Genetic variation in 5HTTLPR is associated with emotional resilience. American journal of medical genetics. Part B, Neuropsychiatric genetics : the official publication of the International Society of Psychiatric Genetics, 150B(7), 900-906. https://doi.org/10.1002/ajmg.b.30916

Sui, B. D., Xu, T. Q., Liu, J. W., Wei, W., Zheng, C. X., Guo, B. L., Wang, Y. Y., \& Yang, Y. L. (2013). Understanding the role of mitochondria in the pathogenesis of chronic pain. Postgraduate medical journal, 89(1058), 709-714. https://doi.org/10.1136/postgradmedj-2012-131068

Sullivan, M. J., Adams, H., Rhodenizer, T., \& Stanish, W. D. (2006). A psychosocial risk factor--targeted intervention for the prevention of chronic pain and disability following whiplash injury. Physical therapy, 86(1), 8-18. https://doi.org/10.1093/ptj/86.1.8

Sullivan, M. J., Thorn, B., Haythornthwaite, J. A., Keefe, F., Martin, M., Bradley, L. A., \& Lefebvre, J. C. (2001). Theoretical perspectives on the relation between catastrophizing and pain. The Clinical journal of pain, 17(1), 52-64. https://doi.org/10.1097/00002508-200103000-00008

Szyf, M., \& Bick, J. (2013). DNA methylation: a mechanism for embedding early life experiences in the genome. Child development, 84(1), 49-57. https://doi.org/10.1111/j.1467-8624.2012.01793.x

Tammimäki, A., \& Männistö, P. T. (2012). Catechol-O-methyltransferase gene polymorphism and chronic human pain: a systematic review and meta-analysis. Pharmacogenetics and genomics, 22(9), 673-691. https://doi.org/10.1097/FPC.0b013e3283560c46

Tander, B., Gunes, S., Boke, O., Alayli, G., Kara, N., Bagci, H., \& Canturk, F. (2008). Polymorphisms of the serotonin-2A receptor and catechol-Omethyltransferase genes: a study on fibromyalgia susceptibility. Rheumatology international, 28(7), 685-691. https://doi.org/10.1007/s00296-008-0525-8

Tegeder, I., Costigan, M., Griffin, R. S., Abele, A., Belfer, I., Schmidt, H., Ehnert, C., Nejim, J., Marian, C., Scholz, J., Wu, T., Allchorne, A., Diatchenko, L., Binshtok, A. M., Goldman, D., Adolph, J., Sama, S., Atlas, S. J., Carlezon, W. A., Parsegian, A., ... Woolf, C. J. (2006). GTP cyclohydrolase and tetrahydrobiopterin regulate pain sensitivity and persistence. Nature medicine, 12(11), 1269-1277. https://doi.org/10.1038/nm1490

Thöny, B., Heizmann, C. W., \& Mattei, M. G. (1995). Human GTP-cyclohydrolase I gene and sepiapterin reductase gene map to region 14q21-q22 and 2p14p12, respectively, by in situ hybridization. Genomics, 26(1), 168-170. https://doi.org/10.1016/0888-7543(95)80101-q

Tour, J., Löfgren, M., Mannerkorpi, K., Gerdle, B., Larsson, A., Palstam, A., Bileviciute-Ljungar, I., Bjersing, J., Martin, I., Ernberg, M., Schalling, M., \& Kosek, E. (2017). Gene-to-gene interactions regulate endogenous pain modulation in fibromyalgia patients and healthy controls-antagonistic effects between opioid and serotonin-related genes. Pain, 158(7), 1194-1203. https://doi.org/10.1097/j.pain.0000000000000896

Tsang, H. T., Connell, J. W., Brown, S. E., Thompson, A., Reid, E., \& Sanderson, C. M. (2006). A systematic analysis of human CHMP protein interactions: additional MIT domain-containing proteins bind to multiple components of the human ESCRT III complex. Genomics, 88(3), 333-346. https://doi.org/10.1016/j.ygeno.2006.04.003

Tunbridge E. M. (2010). The catechol-O-methyltransferase gene: its regulation and polymorphisms. International review of neurobiology, 95, 7-27. https://doi.org/10.1016/B978-0-12-381326-8.00002-8 
Turhanoglu A. D., Yilmaz S., Kaya S., Dursun M., Kararmaz A., Saka G. (2008). The epidemiological aspects of fibromyalgia syndrome in adults living in turkey: a population based study. J Musculoskelet Pain.16:141-7. https://doi.org/10.1080/10582450802161820

Uçeyler, N., Valenza, R., Stock, M., Schedel, R., Sprotte, G., \& Sommer, C. (2006). Reduced levels of antiinflammatory cytokines in patients with chronic widespread pain. Arthritis and rheumatism, 54(8), 2656-2664. https://doi.org/10.1002/art.22026

van Tilburg, M., Parisien, M., Boles, R. G., Drury, G. L., Smith-Voudouris, J., Verma, V., Khoury, S., Chabot-Doré, A. J., Nackley, A. G., Smith, S. B., Whitehead, W. E., Zolnoun, D. A., Slade, G. D., Tchivileva, I., Maixner, W., \& Diatchenko, L. (2020). A genetic polymorphism that is associated with mitochondrial energy metabolism increases risk of fibromyalgia. Pain, 161(12), 2860-2871. https://doi.org/10.1097/j.pain.0000000000001996

Vargas-Alarcon, G., Alvarez-Leon, E., Fragoso, J. M., Vargas, A., Martinez, A., Vallejo, M., \& Martinez-Lavin, M. (2012). A SCN9A gene-encoded dorsal root ganglia sodium channel polymorphism associated with severe fibromyalgia. BMC musculoskeletal disorders, 13, 23. https://doi.org/10.1186/1471-2474$13-23$

Vargas-Alarcón, G., Fragoso, J. M., Cruz-Robles, D., Vargas, A., Martinez, A., Lao-Villadóniga, J. I., García-Fructuoso, F., Vallejo, M., \& Martínez-Lavín, M. (2009). Association of adrenergic receptor gene polymorphisms with different fibromyalgia syndrome domains. Arthritis and rheumatism, 60(7), 21692173. https://doi.org/10.1002/art.24655

Vargas-Alarcón, G., Fragoso, J. M., Cruz-Robles, D., Vargas, A., Vargas, A., Lao-Villadóniga, J. I., García-Fructuoso, F., Ramos-Kuri, M., Hernández, F., Springall, R., Bojalil, R., Vallejo, M., \& Martínez-Lavín, M. (2007). Catechol-O-methyltransferase gene haplotypes in Mexican and Spanish patients with fibromyalgia. Arthritis research \& therapy, 9(5), R110. https://doi.org/10.1186/ar2316

Walitt, B., Nahin, R. L., Katz, R. S., Bergman, M. J., \& Wolfe, F. (2015). The Prevalence and Characteristics of Fibromyalgia in the 2012 National Health Interview Survey. PloS one, 10(9), e0138024. https://doi.org/10.1371/journal.pone.0138024

Wan, L., Li, Y., Zhang, Z., Sun, Z., He, Y., \& Li, R. (2018). Methylenetetrahydrofolate reductase and psychiatric diseases. Translational psychiatry, 8(1), 242. https://doi.org/10.1038/s41398-018-0276-6

Wang, H., Moser, M., Schiltenwolf, M., \& Buchner, M. (2008). Circulating cytokine levels compared to pain in patients with fibromyalgia -- a prospective longitudinal study over 6 months. The Journal of rheumatology, 35(7), 1366-1370.

Weiss, B., Mertz, A., Schröck, E., Koenen, M., \& Rappold, G. (1995). Assignment of a human homolog of the mouse Htr3 receptor gene to chromosome 11q23.1-q23.2. Genomics, 29(1), 304-305. https://doi.org/10.1006/geno.1995.1254

Williams, J., Spurlock, G., McGuffin, P., Mallet, J., Nöthen, M. M., Gill, M., Aschauer, H., Nylander, P. O., Macciardi, F., \& Owen, M. J. (1996). Association between schizophrenia and T102C polymorphism of the 5-hydroxytryptamine type 2a-receptor gene. European Multicentre Association Study of Schizophrenia (EMASS) Group. Lancet (London, England), 347(9011), 1294-1296. https://doi.org/10.1016/s0140-6736(96)90939-3

Wolfe, F., Clauw, D. J., Fitzcharles, M. A., Goldenberg, D. L., Häuser, W., Katz, R. L., Mease, P. J., Russell, A. S., Russell, I. J., \& Walitt, B. (2016). 2016 Revisions to the 2010/2011 fibromyalgia diagnostic criteria. Seminars in arthritis and rheumatism, 46(3), 319-329. https://doi.org/10.1016/j.semarthrit.2016.08.012

Wolfe, F., Clauw, D. J., Fitzcharles, M. A., Goldenberg, D. L., Häuser, W., Katz, R. S., Mease, P., Russell, A. S., Russell, I. J., \& Winfield, J. B. (2011). Fibromyalgia criteria and severity scales for clinical and epidemiological studies: a modification of the ACR Preliminary Diagnostic Criteria for Fibromyalgia. The Journal of rheumatology, 38(6), 1113-1122. https://doi.org/10.3899/jrheum.100594

Wolfe, F., Clauw, D. J., Fitzcharles, M. A., Goldenberg, D. L., Katz, R. S., Mease, P., Russell, A. S., Russell, I. J., Winfield, J. B., \& Yunus, M. B. (2010). The American College of Rheumatology preliminary diagnostic criteria for fibromyalgia and measurement of symptom severity. Arthritis care \& research, 62(5), 600-610. https://doi.org/10.1002/acr.20140

Wolfe, F., Ross, K., Anderson, J., Russell, I. J., \& Hebert, L. (1995). The prevalence and characteristics of fibromyalgia in the general population. Arthritis and rheumatism, 38(1), 19-28. https://doi.org/10.1002/art.1780380104

Wolfe, F., Russell, I. J., Vipraio, G., Ross, K., \& Anderson, J. (1997). Serotonin levels, pain threshold, and fibromyalgia symptoms in the general population. The Journal of rheumatology, 24(3), 555-559.

Wolfe, F., Smythe, H. A., Yunus, M. B., Bennett, R. M., Bombardier, C., Goldenberg, D. L., Tugwell, P., Campbell, S. M., Abeles, M., \& Clark, P. (1990). The American College of Rheumatology 1990 Criteria for the Classification of Fibromyalgia. Report of the Multicenter Criteria Committee. Arthritis and rheumatism, 33(2), 160-172. https://doi.org/10.1002/art.1780330203

Xiao, Y., He, W., \& Russell, I. J. (2011). Genetic polymorphisms of the beta2-adrenergic receptor relate to guanosine protein-coupled stimulator receptor dysfunction in fibromyalgia syndrome. The Journal of rheumatology, 38(6), 1095-1103. https://doi.org/10.3899/jrheum.101104

Xiao, Y., Russell, I. J., \& Liu, Y. G. (2012). A brain-derived neurotrophic factor polymorphism Val66Met identifies fibromyalgia syndrome subgroup with higher body mass index and C-reactive protein. Rheumatology international, 32(8), 2479-2485. https://doi.org/10.1007/s00296-011-1990-z

Yang-Feng, T. L., Xue, F. Y., Zhong, W. W., Cotecchia, S., Frielle, T., Caron, M. G., Lefkowitz, R. J., \& Francke, U. (1990). Chromosomal organization of adrenergic receptor genes. Proceedings of the National Academy of Sciences of the United States of America, 87(4), 1516-1520. https://doi.org/10.1073/pnas.87.4.1516

Yigit, S., Inanir, A., Tekcan, A., Inanir, S., Tural, S., \& Ates, O. (2013). Association between fibromyalgia syndrome and polymorphism of the IL-4 gene in a Turkish population. Gene, 527(1), 62-64. https://doi.org/10.1016/j.gene.2013.04.020

Yunus M. B. (2015). Editorial review: an update on central sensitivity syndromes and the issues of nosology and psychobiology. Current rheumatology reviews, 11(2), 70-85. https://doi.org/10.2174/157339711102150702112236 
Research, Society and Development, v. 11, n. 3, e11211326421, 2022

(CC BY 4.0) | ISSN 2525-3409 | DOI: http://dx.doi.org/10.33448/rsd-v11i3.26421

Zennaro, M. C., Souque, A., Viengchareun, S., Poisson, E., \& Lombès, M. (2001). A new human MR splice variant is a ligand-independent transactivator modulating corticosteroid action. Molecular endocrinology (Baltimore, Md.), 15(9), 1586-1598. https://doi.org/10.1210/mend.15.9.0689

Zhao, M., Chen, L., Yang, J., Han, D., Fang, D., Qiu, X., Yang, X., Qiao, Z., Ma, J., Wang, L., Jiang, S., Song, X., Zhou, J., Zhang, J., Chen, M., Qi, D., Yang, Y., \& Pan, H. (2018). BDNF Val66Met polymorphism, life stress and depression: A meta-analysis of gene-environment interaction. Journal of affective disorders, 227, 226-235. https://doi.org/10.1016/j.jad.2017.10.024

Żmudzka, E., Sałaciak, K., Sapa, J., \& Pytka, K. (2018). Serotonin receptors in depression and anxiety: Insights from animal studies. Life sciences, 210, 106124. https://doi.org/10.1016/j.lfs.2018.08.050

Zorina-Lichtenwalter, K., Meloto, C. B., Khoury, S., \& Diatchenko, L. (2016). Genetic predictors of human chronic pain conditions. Neuroscience, 338, 3662. https://doi.org/10.1016/j.neuroscience.2016.04.041 